\title{
REVIEW
}

\section{The Mysteries of Mammatus Clouds: Observations and Formation Mechanisms}

\author{
David M. Schultz, ${ }^{*}+$ Katharine M. Kanak,* Jerry M. Straka, ${ }^{*}$ Robert J. Trapp, \\ Brent A. Gordon, $\&$ Dusan S. Zrnić, ${ }^{+}$George H. Bryan, ${ }^{* *}$ Adam J. Durant, ${ }^{++}$ \\ Timothy J. Garrett, \#\# Petra M. Klein, \# and Douglas K. Lilly@@ \\ * Cooperative Institute for Mesoscale Meteorological Studies, University of Oklahoma, Norman, Oklahoma \\ + NOAA/National Severe Storms Laboratory, Norman, Oklahoma \\ \# School of Meteorology, University of Oklahoma, Norman, Oklahoma \\ @ Department of Earth and Atmospheric Sciences, Purdue University, West Lafayette, Indiana \\ \& NOAA/NWS/NCEP, Camp Springs, Maryland \\ ** National Center for Atmospheric Research, Boulder, Colorado \\ ++ Department of Geological/Mining Engineering \& Sciences, Michigan Technological University, Houghton, Michigan \\ \#\# Department of Meteorology, University of Utah, Salt Lake City, Utah \\ @@University of Nebraska at Kearney, Kearney, Nebraska
}

(Manuscript received 18 August 2005, in final form 20 January 2006)

\begin{abstract}
Mammatus clouds are an intriguing enigma of atmospheric fluid dynamics and cloud physics. Most commonly observed on the underside of cumulonimbus anvils, mammatus also occur on the underside of cirrus, cirrocumulus, altocumulus, altostratus, and stratocumulus, as well as in contrails from jet aircraft and pyrocumulus ash clouds from volcanic eruptions. Despite their aesthetic appearance, mammatus have been the subject of few quantitative research studies. Observations of mammatus have been obtained largely through serendipitous opportunities with a single observing system (e.g., aircraft penetrations, visual observations, lidar, radar) or tangential observations from field programs with other objectives. Theories describing mammatus remain untested, as adequate measurements for validation do not exist because of the small distance scales and short time scales of mammatus. Modeling studies of mammatus are virtually nonexistent. As a result, relatively little is known about the environment, formation mechanisms, properties, microphysics, and dynamics of mammatus.

This paper presents a review of mammatus clouds that addresses these mysteries. Previous observations of mammatus and proposed formation mechanisms are discussed. These hypothesized mechanisms are anvil subsidence, subcloud evaporation/sublimation, melting, hydrometeor fallout, cloud-base detrainment instability, radiative effects, gravity waves, Kelvin-Helmholtz instability, Rayleigh-Taylor instability, and Rayleigh-Bénard-like convection. Other issues addressed in this paper include whether mammatus are composed of ice or liquid water hydrometeors, why mammatus are smooth, what controls the temporal and spatial scales and organization of individual mammatus lobes, and what are the properties of volcanic ash clouds that produce mammatus? The similarities and differences between mammatus, virga, stalactites, and reticular clouds are also discussed. Finally, because much still remains to be learned, research opportunities are described for using mammatus as a window into the microphysical, turbulent, and dynamical processes occurring on the underside of clouds.
\end{abstract}

\section{Introduction}

The Glossary of Meteorology defines mammatus clouds (or mamma) as "hanging protuberances, like pouches, on the undersurface of a cloud" (Glickman

Corresponding author address: Dr. David M. Schultz, NOAA/ National Severe Storms Laboratory/FRDD, Suite 4356, Norman, OK 73072-7326.

E-mail: david.schultz@noaa.gov
2000, p. 471). The word mammatus is Latin for "having breasts." A characteristic of mammatus is their often smooth, laminar appearance, which makes them some of the most distinctive clouds in our atmosphere (Figs. 1 and 2). Their aesthetic appearance when illuminated by the colors of sunset, have made mammatus a popular subject of photographers and artists. For example, Gedzelman (1989) noted that mammatus have appeared in paintings as early as the 1500 s.

Mammatus often occur on the edges and sloping un- 

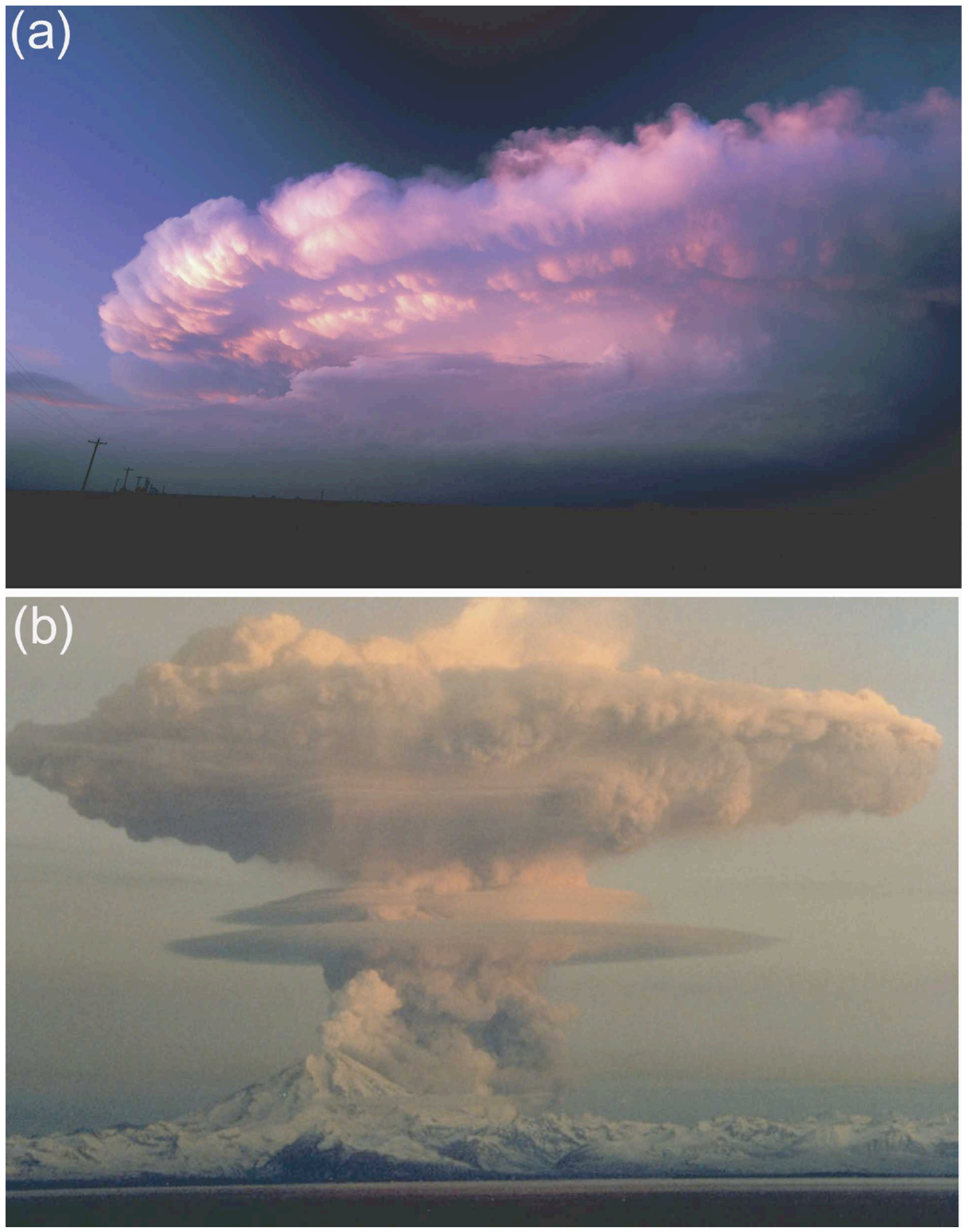

FIG. 1. (a) Cumulonimbus anvil mammatus organized into lines, possibly along radiating gravity waves: 5 May 2002, east of Silverton, TX (copyright C. A. Doswell III). (b) Pyrocumulus mammatus associated with the eruption of Mount Redoubt on 21 Apr 1990 (photo by R. J. Clucas, from the U.S. Geological Survey Digital Data Series, DDS-039).

derside of cumulonimbus (e.g., Fig. 1a) and have been observed on both the upshear and downshear sides of the outflow anvil. Although cumulonimbus anvil mammatus is the most commonly noted and photographed, mammatus can occur in other cloud types as well. Ley
(1894, pp. 84-86, 104), who appears to have originated the term mammatus (Berry et al. 1945, p. 891), identified two types: cumulonimbus anvil mammatus and cumulostratus (now known as stratocumulus) mammatus (e.g., Fig. 2e). German meteorologists in the early 


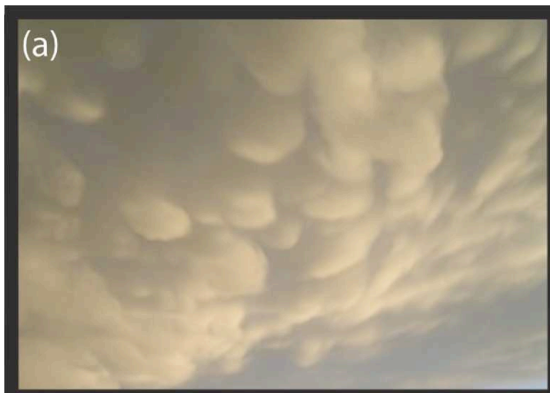

\section{(b)}

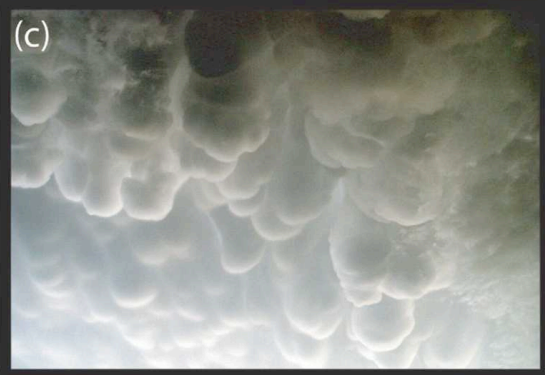

(d)

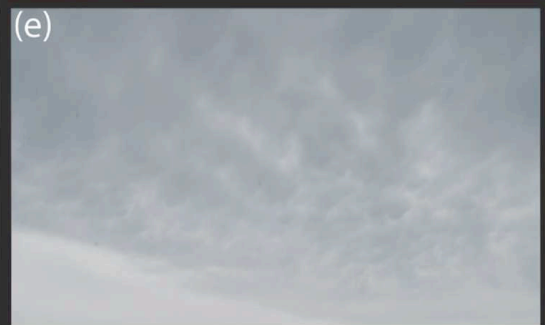

(g)

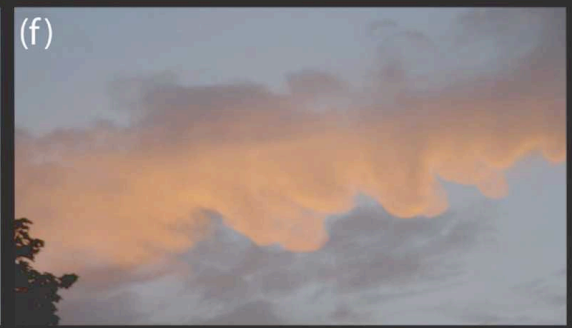

(h)



FIG. 2. (a) Cumulonimbus anvil mammatus: 25 Mar 2005, Salt Lake City, UT (copyright J. Steenburgh). (b) Mammatus with ragged edges: 29 Jun 2004, Norman, OK (copyright K. Kanak and J. Straka). (c) Well-developed cumulonimbus anvil mammatus lobes: 29 May 2004, near Belleville, KS (copyright V. Doswell). (d) Cumulonimbus anvil mammatus arranged in lines, showing blue sky between lobes: 8 May 2005, Norman, OK (copyright C. A. Doswell III). (e) Stratocumulus mammatus: 3 Aug 2003, Ouachita National Forest, OK (copyright D. Schultz). (f) Mammatus that formed on a cumulonimbus anvil that had all nearly evaporated except for the leading edge: 2047 CDT 7 Jun 2004, Norman, OK (copyright K. Kanak and J. Straka). (g) Mammatus exhibiting breaking Kelvin-Helmholtz waves: 2 Aug 1992, Norman, OK (copyright K. Kanak and J. Straka). (h) Mammatus in the ash cloud from the Mount St. Helens eruption at 0832 Pacific daylight time (PDT) 18 May 1980: picture taken at about 0900 PDT 18 May 1980, Richland, WA (copyright M. Orgill).

twentieth century also recognized that mammatus clouds could occur in association with altostratus, altocumulus, and cirrus. Scorer (1972) noted that mammatus can occur on falling rain or snow below a cloud base or on streaks of falling ice crystals. Ludlam and Scorer (1953) observed mammatus-like features as jetaircraft condensation trails broke up into pendulous lumps. Mammatus have even been observed on pyrocu- 
mulus clouds from volcanic eruptions (e.g., Stith 1995, p. 911; Figs. $1 \mathrm{~b}$ and $2 \mathrm{~h}$ and section $4 \mathrm{~g}$ in the present paper). Note the similarities between cumulonimbus anvil mammatus and pyrocumulus mammatus in terms of the structures of the mammatus and their locations on the clouds (cf. Figs. 1a,b). The variety of situations under which mammatus form led Ley (1894) and Berg (1938), for example, to argue that these different types of mammatus are likely formed by different processes.

Not all mammatus look the same, however. Sometimes the surfaces of mammatus are laminar (e.g., Fig. 2a), whereas other times they are ragged (e.g., Fig. 2b). Sometimes they can penetrate quite deeply from the cloud base into the subcloud air (e.g., Fig. 2c). Sometimes they can occur on a thin part of the anvil so that blue sky is seen between the lobes (e.g., Figs. 2d,f).

Because they are not directly related to significant weather events on the ground and they do not apparently hold insights into forecasting severe convective storms, mammatus generally have been viewed as no more than a curiosity in the atmosphere. Consequently, published research on mammatus is rather limited, and what literature exists is either highly speculative or severely constrained by the limited nature of the observations. The majority of observations of mammatus derives from serendipitous measurements using single observing systems or from field programs with objectives that exclude studying mammatus. In some cases, although mammatus-like structures may be apparent in radar data or numerical model output, visual confirmation of mammatus may not even exist. Theories for mammatus abound, but have rarely been rigorously tested with observed data. Textbooks at all levels (undergraduate, graduate, general public) parrot these theories, leading to the further spread of misinformation. In addition, laboratory experiments and numerical model simulations of mammatus initialized from idealized or real-data initial conditions are lacking. As a result, relatively little is known about the environment, origin, structure, size, microphysical properties, and dynamics of mammatus.

The purpose of this paper is to discuss observations of mammatus and to critically evaluate existing theories. In this paper, we choose to broaden our scope to consider mammatus and mammatus-like structures whether or not they have been visually identified. Observations with visual confirmation of mammatus structures are especially valued because that seems to be the primary means of identifying these curious cloud structures, as they have been defined in the past. Furthermore, because the atmosphere often resists being pigeonholed into convenient little bins, this paper will benefit from taking a broader perspective of the features on the undersides of clouds.

In section 2, previous observations of mammatus are reviewed. Particular attention is paid to the shapes, structures, microphysical compositions, and associations with different parent clouds. An informed discussion of hypothesized formation mechanisms for mammatus is presented in section 3. These theories are evaluated to the extent possible, in light of the available observational data. Section 4 contains discussions of other issues regarding mammatus, including the types of hydrometeors, their smoothness, and the factors that control their spatial/temporal scales and organization. The nature of mammatus formed in pyrocumulus from volcanic eruptions is also discussed, as are the similarities and differences between mammatus, virga, stalactites, and reticular clouds. Section 5 concludes this paper, addressing the types of observational data and numerical-model experimentation needed to begin to resolve some of these questions.

\section{Observations of mammatus}

The literature on mammatus from the first half of the twentieth century comes mostly from German scientists and is discussed in section 2 a. Later quantitative observations of mammatus, described in section $2 \mathrm{~b}$, are rather limited, amounting to perhaps a dozen studies (Table 1). Recently, several studies have presented observations of cirrus mammatus; these studies are reviewed in section $2 \mathrm{c}$. In section $2 \mathrm{~d}$, we present data from a previously unpublished mammatus event, and we revisit data from another event.

\section{a. Early literature: $1900-48$}

This period of mammatus research within the German literature seems to have been inspired by Osthoff (1906). His seven-and-a-half-page paper described his observations of 67 mammatus events over 21 years. He found that mammatus were 10 times more likely to occur during the summer than winter, with more than half of the events occurring during 1400-1700 local standard time (LST). Almost half (42.6\%) of the events were associated with thunderstorms, squalls, or cumulonimbus, whereas $31.5 \%$ were associated with stratocumulus, $24.1 \%$ were associated with altocumulus or middle clouds, and $1.9 \%$ were associated with nimbus. His drawings of mammatus showed the variety of structures he observed.

Inspired by Osthoff's work, Wegener (1909) argued that discontinuities in temperature and wind across the cloud base would be observed in cumulonimbus anvil 
TABLE 1. Previous observational studies of mammatus. Types of observations: $A=$ aircraft, $G D=$ ground-based Doppler radar, $\mathrm{AD}=$ airborne Doppler radar, $\mathrm{VD}=$ vertically pointing Doppler radar, $\mathrm{R}=$ rawinsonde, $\mathrm{L}=$ lidar, $\mathrm{P}=$ stereo photogrammetry. $\mathrm{N} / \mathrm{A}=$ not available. Height is in km MSL.

\begin{tabular}{|c|c|c|c|c|c|c|}
\hline Study & $\begin{array}{c}\text { Pressure }(\mathrm{hPa}) \\
\text { [height }(\mathrm{km})]\end{array}$ & $\begin{array}{c}\text { Temperature } \\
\left({ }^{\circ} \mathrm{C}\right)\end{array}$ & $\begin{array}{l}\text { Horizontal } \\
\text { scale }(\mathrm{km})\end{array}$ & Environment & Obs & $w\left(\mathrm{~m} \mathrm{~s}^{-1}\right)$ \\
\hline Hlad (1944) I & {$[1.28]$} & +15 & N/A & Thunderstorm & $\mathrm{R}$ & N/A \\
\hline Hlad (1944) II & {$[3.66]$} & +1 & N/A & Altostratus & $\mathrm{R}$ & N/A \\
\hline Hlad (1944) III & [3.96] & -1 & N/A & Thunderstorm & $\mathrm{R} / \mathrm{A}$ & N/A \\
\hline Clarke (1962) & $600[4]$ & -1 to -2 & $0.25-0.75$ & Cold front & $\mathrm{R}$ & N/A \\
\hline Warner (1973) & {$[5-6.5]$} & N/A & $\begin{array}{c}0.12-1.05 \\
\text { mean } 0.35\end{array}$ & Hailstorm & $\mathrm{P}$ & $\begin{array}{c}-3.1 \text { to }-1.2 \\
\text { mean }-2.3\end{array}$ \\
\hline Stith (1995) & $394[7.3]$ & -25 & $2-3$ & Hailstorm (supercell) & A & -2.5 to +1.0 \\
\hline Martner (1995) & {$[3-5]$} & +1 to -11 & 1.1 & Rain shower with anvil & $\mathrm{VD}$ & $\begin{array}{l}-3 \text { to }+0.5 \\
\text { mean }-0.7\end{array}$ \\
\hline Winstead et al. (2001) & $450[7]$ & -20 & $1-3$ & $\begin{array}{l}\text { Stratiform anvil between } \\
\text { supercells }\end{array}$ & $\mathrm{AD}$ & -2 to -3 \\
\hline Wang and Sassen (2005) & [7.4-8] & -37 & $3-7$ & $\begin{array}{l}\text { Cirrostratus transitioning } \\
\text { to altostratus }\end{array}$ & $\mathrm{L} / \mathrm{VD}$ & -2 to +0.5 \\
\hline $\begin{array}{l}\text { Jo et al. (2003) and } \\
\text { Kollias et al. (2005) }\end{array}$ & {$[5-6]$} & $<0$ & $1-3$ & Convective anvil & VD & -5 to +1.5 \\
\hline This study 4 Aug 1992 & {$[5.4-5.9]$} & $<0$ & $0.5-2.0$ & MCC stratiform region & GD/VP & 0.0 to -3.5 \\
\hline This study 14-15 Feb 2000 & 660 [2.97] & -1.7 & $1-2$ & Pre-cold front & GD & N/A \\
\hline
\end{tabular}

mammatus as a result of the anvil spreading horizontally. Because the anvil outflow and the thunderstorm environment would not necessarily have the same temperature and horizontal momentum, a thermal inversion and vertical wind discontinuity may be expected. This argument was supported by future observational evidence, discussed later in this paper.

Clayton (1911) reported on four different cases of mammatus sampled by kite soundings at the Harvard College Astronomical Observatory. Said Clayton (1911, p. 183), "In every case where the lower surface of a cloud is mammated, the cloud is found above an inverted gradient of temperature." Hartmann (1920), in observations of stratus mammatus passing over a mountaintop observing station, observed a dry layer underneath the mammatus in association with an inversion and strong wind shear. Further observations of mammatus by Schneider (1920) from two instrumented kite ascents showed an inversion of $0.7^{\circ}-1.5^{\circ} \mathrm{C}$ at cloud base. While most authors at this time believed that mammatus were convex protuberances hanging down from cloud base, Schmauss (1913) argued, apparently unconvincingly, that an optical effect due to the illumination of the underside of the cloud made it difficult to determine whether mammatus were concave or convex.

Troeger (1921) observed stratus mammatus in association with a $46^{\circ}$ halo around the sun. (The $46^{\circ}$ halo, or great halo, is caused by sunlight being refracted through horizontally falling, pencil-like ice columns with hexagonal cross sections.) This work later prompted him to perform a climatology of 100 cases of mammatus (Troeger 1922), analogous to Osthoff's. Troeger (1922) found that mammatus were 2 or 3 times more likely to occur in summer than winter, compared to Osthoff's (1906) 10 times. The editors of Meteorologische Zeitschrift cautioned that Osthoff (1906) and Troeger (1922) likely had different definitions of mammatus because of Osthoff's lower frequency of mammatus. Like Osthoff (1906), Troeger (1922) also found an afternoon maximum in occurrence. He proposed two different mechanisms for mammatus formation. The first mechanism involved a moist stratus layer moving over a very dry layer with evaporation of the lower part of the cloud resulting in mammatus. The second mechanism occurred in the lower part of fall streaks or cirrus, where wind shear caused the settling particles to slow down, recirculate, and form mammatus. Troeger (1922) appears to have been the first to describe cirrus mammatus, although Bauman (1927) would later claim that his observations of cirrus mammatus were the first reported in the literature. (More discussion on cirrus mammatus can be found in section 2c.)

Of the mammatus research during the first half of the twentieth century, that by Berg (1938) was arguably the most insightful. He discussed three types of mammatus and attributed each type to a different physical process. Altostratus mammatus were attributed to waves due to Kelvin-Helmholtz instability (section 3h) across the inversion at cloud base. What Berg (1938) considered cumulonimbus mammatus were fallstreaks. Altocumulus mammatus cumulogenitus (what would be called cumulonimbus anvil mammatus today) developed 
when the overshooting top of a cumulonimbus hit the tropopause and spread out. Although Berg (1938) recognized the existence of cirrus mammatus, he did not discuss it in detail.

Finally, Wagner (1948) suggested that a slowly subsiding cloud base would generate instability as the cloudy air underwent saturated adiabatic descent and the dry subcloud air underwent dry adiabatic descent. The result of this steepening lapse rate across the cloud base may provide impetus for the formation of mammatus.

\section{b. Recent observations: 1944-present}

Hlad (1944) investigated soundings associated with three cases of mammatus in southern Texas. Two were associated with postconvective environments, whereas the third was associated with a thin altostratus overcast. On one of the postconvective events, Hlad (1944, p. 331) participated in an aircraft flight through the mammatus and described the remarkable experience:

At 13,000 feet [3962 m] we entered the actual mammatus cloud deck, although it didn't appear to be a cloud deck from a technical standpoint. There were vast openings where the visibilities were very good, below we could see trails of very heavy drops, yet there was no rain striking the plane. The turbulence was very light in these openings. Seeking an explanation, we went down to 12,000 feet [ $3658 \mathrm{~m}$ ] and passed under the rain trails.

There was no rain striking the plane at this level either, although looking above us we could see the large drops. Next we entered this "ball" of rain which appeared to be suspended in the air. Inside, the rain drops were very heavy and the turbulence was moderate to heavy. After flying under, over, and through several of these rain "balls," the conclusion was reached that they were the actual "sacks" that gave the cloud deck above its mammatus appearance. These rain "sacks" extended as much as 1000 feet [305 $\mathrm{m}$ ] downward from the main deck and yet no rain fell from any of those that we passed under.

Hlad (1944) concluded that these rain sacks must be suspended by strong upward vertical motion (a hypothesis not verified by later observations from others) and the lower boundary of the sacks were caused by evaporation of the rain drops (evaporation is one possible mechanism for mammatus, see section $3 b$ ).

Clarke (1962) described mammatus on the underside of a cold-frontal rainband of altocumulus and altostratus associated with virga, employing visual observations and surface barograms. This field of mammatus was apparently viewed simultaneously over a $300-500-\mathrm{km}$ long region in Australia. The mammatus were orga- nized into lines believed to be associated with $1.5-\mathrm{hPa}$ surface pressure perturbations moving at $27 \mathrm{~m} \mathrm{~s}^{-1}$. Richardson numbers less than or approximately equal to 0.25 in the region of mammatus suggested to Clarke (1962) that internal gravity waves formed on a low-level inversion due to forcing from the mammatus circulations.

Warner (1973) employed stereo photogrammetry to analyze the characteristics of mammatus in a time-lapse movie of a hailstorm in Alberta. The average lifetime of 14 mammatus lobes was $10 \mathrm{~min}$, the average diameter of 54 lobes was $350 \mathrm{~m}$, and the mean vertical velocity of 13 lobes was $-2.3 \mathrm{~m} \mathrm{~s}^{-1}$, with a range of -3.1 to -1.2 $\mathrm{m} \mathrm{s}^{-1}$ (Table 1).

Stith (1995) flew through two cumulonimbus mammatus lobes over North Dakota using the University of North Dakota Citation aircraft and particle measuring systems. Like Hlad (1944), Stith (1995) also noted that the mammatus were not opaque. Within the lobes, the hydrometeors were composed mostly of aggregated ice particles with some rounded ice particles (i.e., frozen drops). Liquid water was not observed in large quantities. The main descending portions of the mammatus lobes were $0.7^{\circ} \mathrm{C}$ warmer than the ambient air, although not very turbulent (approximately $0.2-0.3 g$, just barely within the range considered light turbulence by pilots). Vertical air motions measured by the plane were comparable to fall speeds for larger ice crystals $\left(\sim 2 \mathrm{~m} \mathrm{~s}^{-1}\right)$, so these falling particles were likely staying within the mammatus lobes.

Martner (1995, 1996) used a vertically pointing, cloud-sensing radar to collect one of the first published, high-resolution, Doppler radar measurements of cumulonimbus anvil mammatus (Fig. 3a). Descent dominated the region where the mammatus formed (Fig. $3 \mathrm{~b}$ ). The variance of the Doppler spectrum (i.e., spectrum width squared) was small within the mammatus lobe and decreased toward the bottom suggesting that turbulence was weak and that the hydrometeors were relatively uniform in fall speed, which would be consistent with aggregated ice particles as their fall speed is only weakly dependent on size. Martner (1995) also showed a strong negative correlation between radar reflectivity factor and vertical velocity (i.e., high radar reflectivity factor was associated with downward velocity), results that would be later confirmed by other studies (e.g., Jo et al. 2003; Wang and Sassen 2006).

Winstead et al. (2001) obtained airborne Doppler radar measurements of cumulonimbus anvil mammatus and found weak turbulent motions within the mammatus and strong turbulence within the anvil. They also found no decrease in the variance of the Doppler spectrum toward the cloud bottom, in contrast to that ob- 


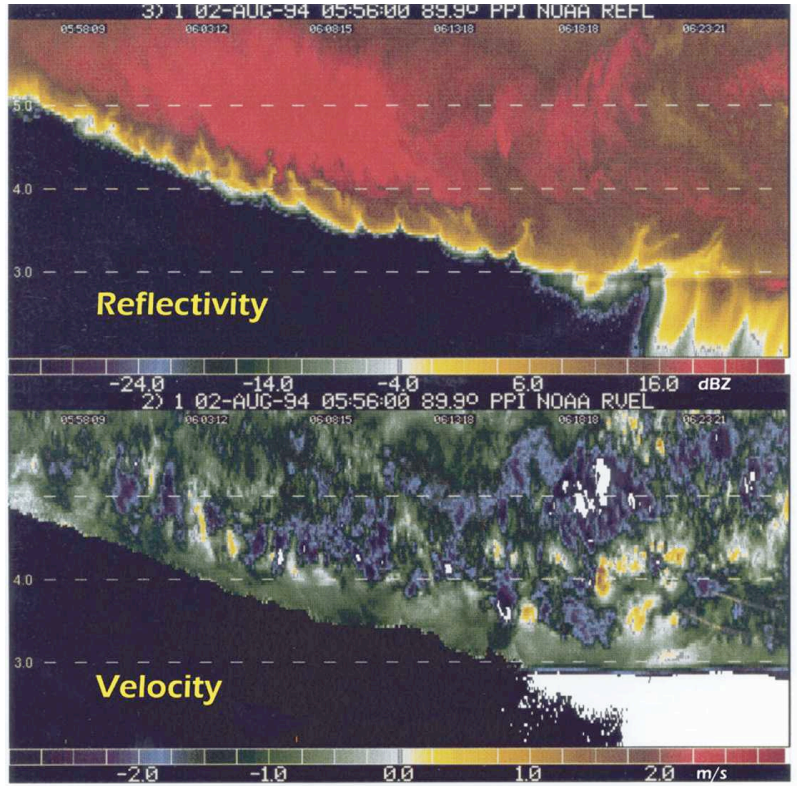

FIG. 3. Vertically pointing cloud-sensing (35-GHz) Doppler radar measurements of (a) reflectivity and (b) mean vertical velocity on 0556-0624 UTC 2 Aug 1994, north-central Manitoba, Canada. [Previously published in Martner $(1995,1996)$. Figure courtesy of B. Martner].

served by Martner (1995) for the bottom of the mammatus and Kollias et al. (2005) for the edges of the mammatus, suggesting either that turbulence did not decrease toward the bottom or that the size distribution of the hydrometeors did not change. Winstead et al. (2001) documented the first radar cross section of the internal circulation of a mammatus lobe (Fig. 4). The internal circulation featured strong descent of several meters per second in the core and weak ascent around the edges, although the geometry of the radar scan implied a significant horizontal wind component existed. Similar observations of the lobe structure of mammatus at the base of a 6-km-deep layer of cirrus using a cloudsensing vertically pointing Doppler radar in Florida were obtained by Kollias et al. (2005). They found descent of up to $-5 \mathrm{~m} \mathrm{~s}^{-1}$ in the mammatus core, decreasing toward the base of and the edges of the mammatus lobes, and weaker ascent (as much as $+1.5 \mathrm{~m} \mathrm{~s}^{-1}$ ) along the edges, reminiscent of an upside-down cumulus turret.

\section{c. Recent observations of cirrus mammatus}

First described by Troeger (1922), Bauman (1927), and Ludlam (1948), cirrus mammatus were not discussed much until the advent of ground-based remote sensing equipment like lidars. Because of the flat, high cloud base and the small size of the mammatus lobes (e.g., Figs. 5a and 6), observation of cirrus mammatus

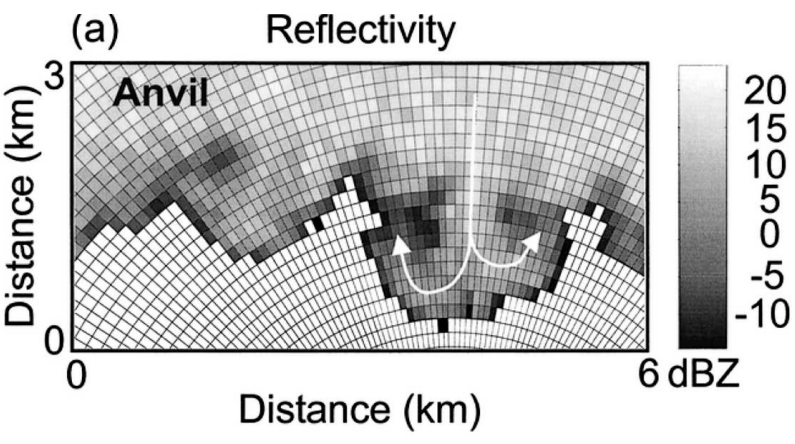

(b)

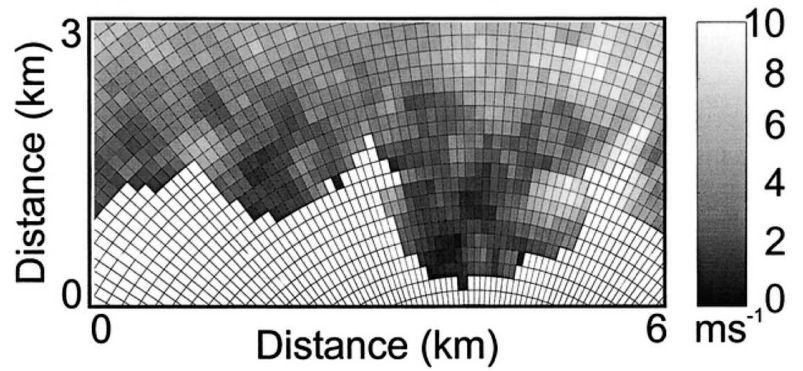

FIG. 4. Pseudo-RHI plot of (a) reflectivity and (b) radial velocity for a representative mammatus lobe. This mammatus cloud was almost directly above the aircraft flight track (Winstead et al. 2001, their Fig. 6).

with the naked eye is difficult unless the setting sun illuminates them (Fig. 5b). In contrast to the smooth laminar protuberances in most mammatus clouds, cirrus mammatus have sharp broken edges (Fig. 6). Wang and Sassen (2006) argued that two types of cirrus mammatus exist: those associated with cirrus uncinus or fallstreaks (e.g., Scorer 1958; Scorer 1972; Ludlam 1980) and those associated with cirrostratus or cirrostratusaltostratus transition clouds. Recent pictures of cirrus mammatus can be found in Sassen et al. (1995, their Figs. 11 and 22), Sassen et al. (2001, their Figs. 7, 8, and 15), Quante et al. (2002), and Sassen (2002, his Plates 2.3 and 2.4, and Fig. 2.3). For example, Sassen et al. (2001) and Sassen (2002) used a vertically pointing lidar to observe the detailed turbulent structure of cirrus mammatus and cumulonimbus anvil mammatus (Figs. 6 and 7).

Platt et al. (2002) examined the structure of a field of cirrus mammatus in decaying tropical convection using vertically pointing lidars and millimeter-wavelength radar. Using a lidar radiometer, Platt et al. (2002) found in-cloud cooling of about $10^{\circ} \mathrm{C}$ within $1 \mathrm{~km}$ of cloud base, suggesting that sublimation of ice crystals was occurring. Wang and Sassen (2006) arrived at a similar conclusion by showing smaller linear depolarization ratios along the edges of the mammatus. This observation 

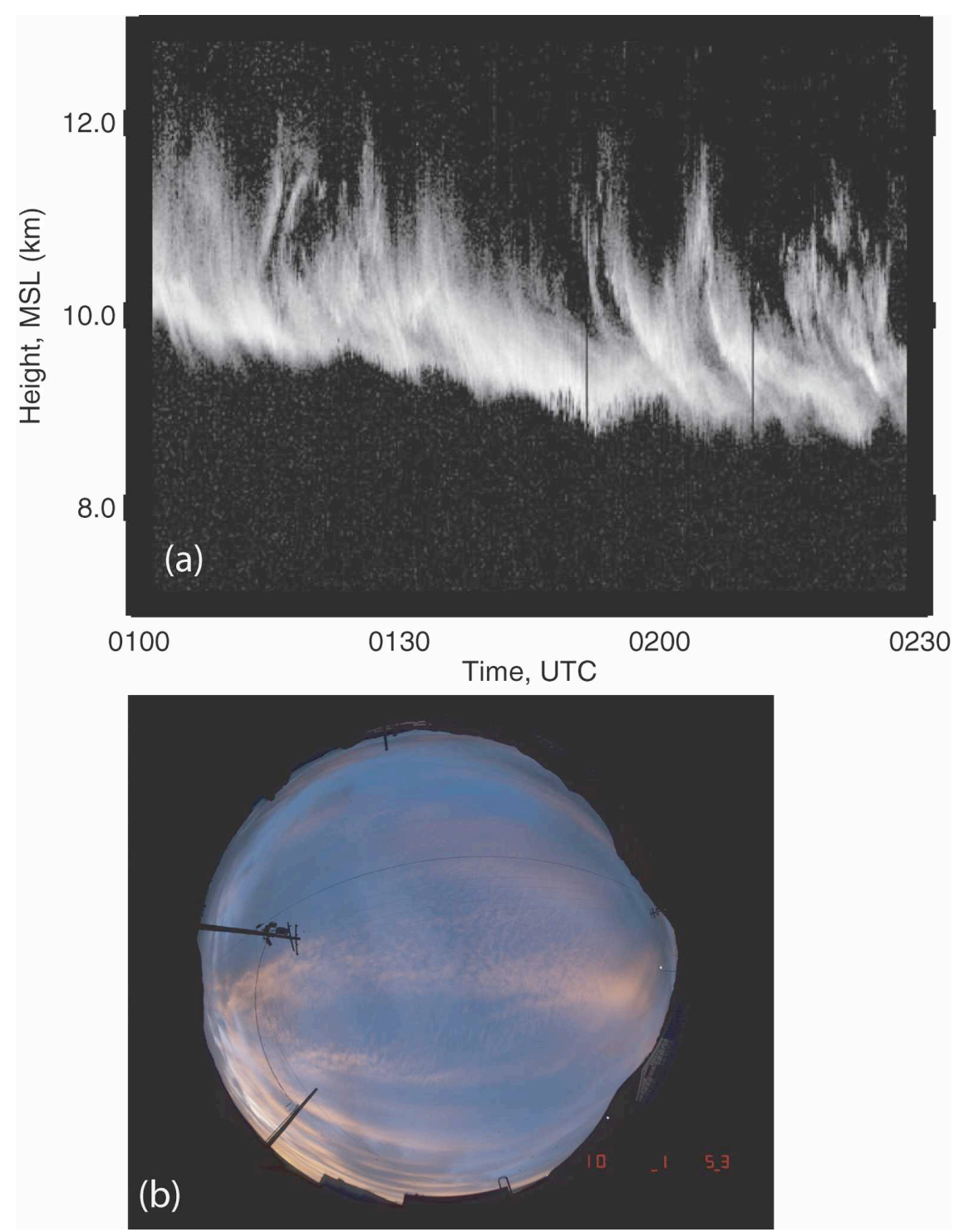

FIG. 5. (a) Cloud polarization lidar returned-power displays of cirrus mammatus on 01000230 UTC 10 Sep 1994, Salt Lake City, UT; (b) upward-looking fish-eye lens photo of field of cirrus mammatus on 0153 UTC 10 Sep 1994 (courtesy of K. Sassen).

suggested smaller ice crystals along the edges, indicating sublimation of the ice crystals in the dry air surrounding the protuberances.

Wang and Sassen (2006) identified 25 cases of cirrus mammatus over $9 \mathrm{yr}$ using the high-cloud datasets from the Facility for Atmospheric Remote Sensing in Salt Lake City, Utah (Sassen et al. 2001). The horizontal scale of the cirrus mammatus was $0.5-8.0 \mathrm{~km}$, with a vertical scale of $0.3-1.1 \mathrm{~km}$ below cloud base. Wang and Sassen (2006) presented a case where both cirrus mammatus and cumulonimbus (anvil) mammatus occurred within the same cloud (Fig. 6). They argued that the smooth outline of cumulonimbus anvil mammatus was a result of a hydrometeor fallout front (see section 3d), which was absent in the coarser-edged cirrus mammatus. Because both types occurred in similar large-scale environments, Wang and Sassen (2006) argued that the local microphysical properties and downdraft velocities must be responsible for the differences, a point returned to later in this paper.

\section{d. Other observed cases}

We now present two additional observations of mammatus using radar. The first occurrence was collected from the National Severe Storms Laboratory's (NSSL) Cimarron dual-polarization Doppler radar (Zahrai and 

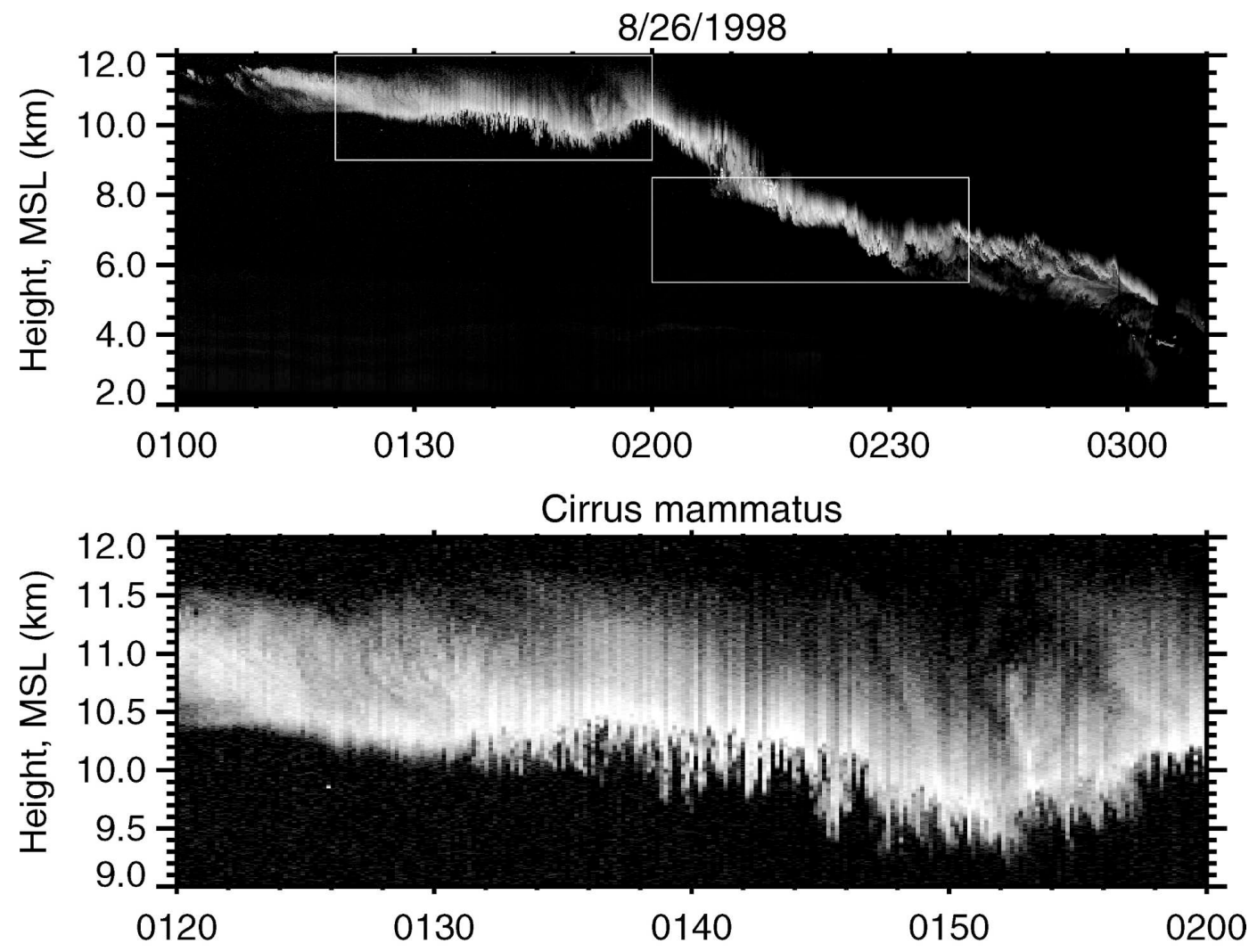

Anvil mammatus

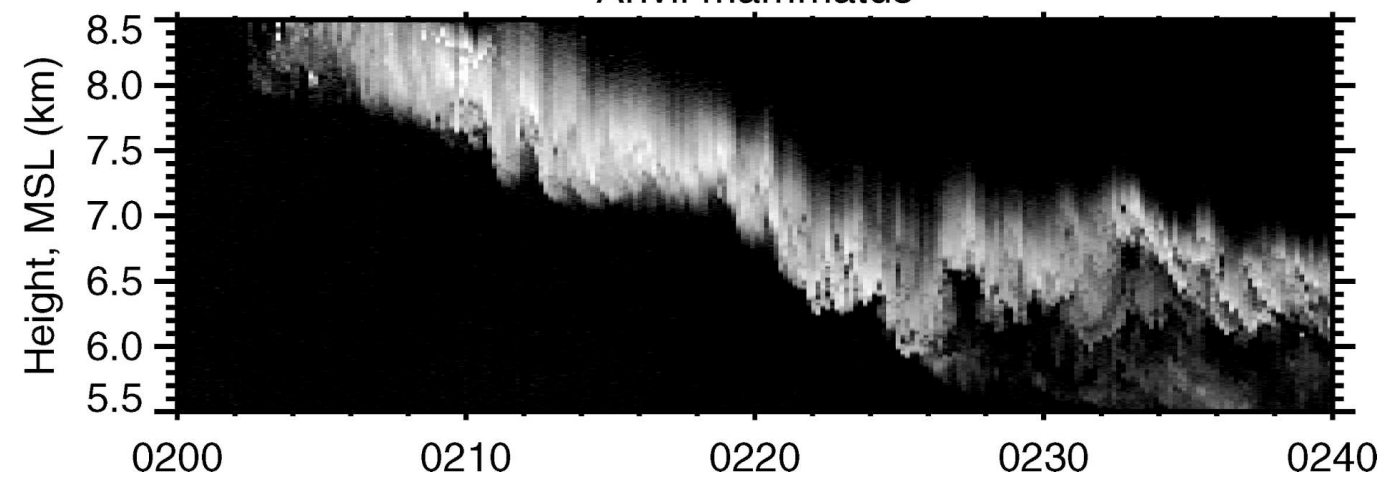

FIG. 6. Cloud polarization lidar returned-power displays of an anvil case on 26 Aug 1998 where mammatus first developed at cirrus heights and later developed in a dense anvil. The expanded view of the cirrus and anvil mammatus illustrates the structural differences: cirrus mammatus are relatively narrow and are sharply outlined, whereas cumulonimbus anvil mammatus are smooth cauliflower-like protuberances (Wang and Sassen 2005, their Fig. 11).

Zrnić 1993). The second was collected with one of the University of Oklahoma Doppler on Wheels (DOW2; Wurman et al. 1997) during the Intermountain Precipitation Experiment (IPEX; Schultz et al. 2002).

\section{1) Central Oklahoma: 4 August 1992}

On 4 August 1992, the Cimarron dual-polarization radar captured the decaying stage of a mesoscale convective complex (MCC) that passed over central Okla- homa (Gordon 1995; Gordon et al. 1995). The radar antenna was pointed vertically while the stratiform region of the MCC passed overhead at 1128-1134 UTC. Time versus height reflectivity data (Fig. 8a) indicated the anvil occupied 5.5-7.0 km AGL, below which hung several perturbations (toward the right-hand side of Fig. 8a). The appearance of these perturbations on radar suggests, although we have no visual confirmation, that these structures were mammatus. 




FIG. 7. Consecutive $\pm 10^{\circ}$ elevation angle scans of returned energy collected by the polarization diversity lidar from the Facility for Atmospheric Remote Sensing (FARS) 0225:360228:38 UTC 26 Aug 1998 at a $1.0^{\circ} \mathrm{s}^{-1}$ scan rate, showing high-resolution slices through turbulent cumulonimbus anvil mammatus (Sassen et al. 2001, their Fig. 8).

To determine the size of these mammatus, the features were assumed to be advected by the mean wind speed at that level, and space-time conversion was applied. Averaging the radial wind at constant ranges from the radar (i.e., Velocity Azimuth Display or VAD) produced a mean wind at $6 \mathrm{~km} \mathrm{AGL}$ of $270^{\circ}$ at $15 \mathrm{~m} \mathrm{~s}^{-1}$. Consequently, the horizontal diameter of the perturbations was approximately $500 \mathrm{~m}$. Although the vertical extent of the perturbations in radar reflectivity factor was also about $500 \mathrm{~m}$, the circulation, as estimated from the vertical-velocity measurements, was a little deeper, about $1 \mathrm{~km}$ (Fig. 8b), consistent with previous observations of deeper vertical circulations inside the cloud associated with some mammatus (e.g., Martner 1995; Winstead et al. 2001).

The corresponding velocity field (Fig. 8b) shows descent in areas of high reflectivity (greater than $7 \mathrm{dBZ}$ ) and ascent in areas of low reflectivity (less than $7 \mathrm{dBZ}$ ), consistent with previous studies (e.g., Martner 1995; Jo et al. 2003; Wang and Sassen 2006). The descent ranged from $-1 \mathrm{~m} \mathrm{~s}^{-1}$ to $-4.5 \mathrm{~m} \mathrm{~s}^{-1}$, whereas the ascent reached $+1 \mathrm{~m} \mathrm{~s}^{-1}$. The broad region of weak ascent $\left(<+1 \mathrm{~m} \mathrm{~s}^{-1}\right)$ below the mammatus (Fig. 8b) is indicative of the slow mesoscale ascent expected within the MCC (e.g., Houze et al. 1989). Immediately after collecting data with the radar pointing vertically, several range-height indicators (RHIs) were performed. These RHIs (not shown) confirm the structures observed during the vertically pointing mode.
Spectrum width (Fig. 8c) in the clouds was relatively low (less than $2 \mathrm{~m} \mathrm{~s}^{-1}$ ), implying little turbulence. In regions of small reflectivity, noise dominated signal, producing areas of large spectrum width (3-4 $\mathrm{m} \mathrm{s}^{-1}$ ). The Norman sounding was released within 20-30 min of the mammatus event about $41 \mathrm{~km}$ southeast of the Cimarron radar, but only reached about $580 \mathrm{hPa}$ (not shown). The freezing level was at about $3.6 \mathrm{~km}$ MSL (3.1 km AGL) and a dry subcloud layer was present, both features typical of many mammatus events. The band of low correlation coefficient as observed by the radar at $3.5 \mathrm{~km}$ AGL (Fig. 8d) indicated the melting layer (e.g., Zrnić et al. 1993; Straka et al. 2000). That cloud base was 5.0-5.5 km AGL (Fig. 8a) implies the mammatus were above the freezing level and thus contained primarily ice-phase hydrometeors.

\section{2) Northern Utah: 14-15 February 2000}

This mammatus event occurred during IPEX, a field program designed to improve wintertime quantitative prediction of precipitation over the Intermountain West of the United States (Schultz et al. 2002). Known as the Valentine's Day windstorm, this cold front was the focus of IPEX's fourth intensive observing period (IOP 4). The microscale structure and evolution of the front in northern Utah was described by Schultz and Trapp (2003).

The mammatus were observed on the underside of a forward-sloping cloud in advance of a surface cold front 

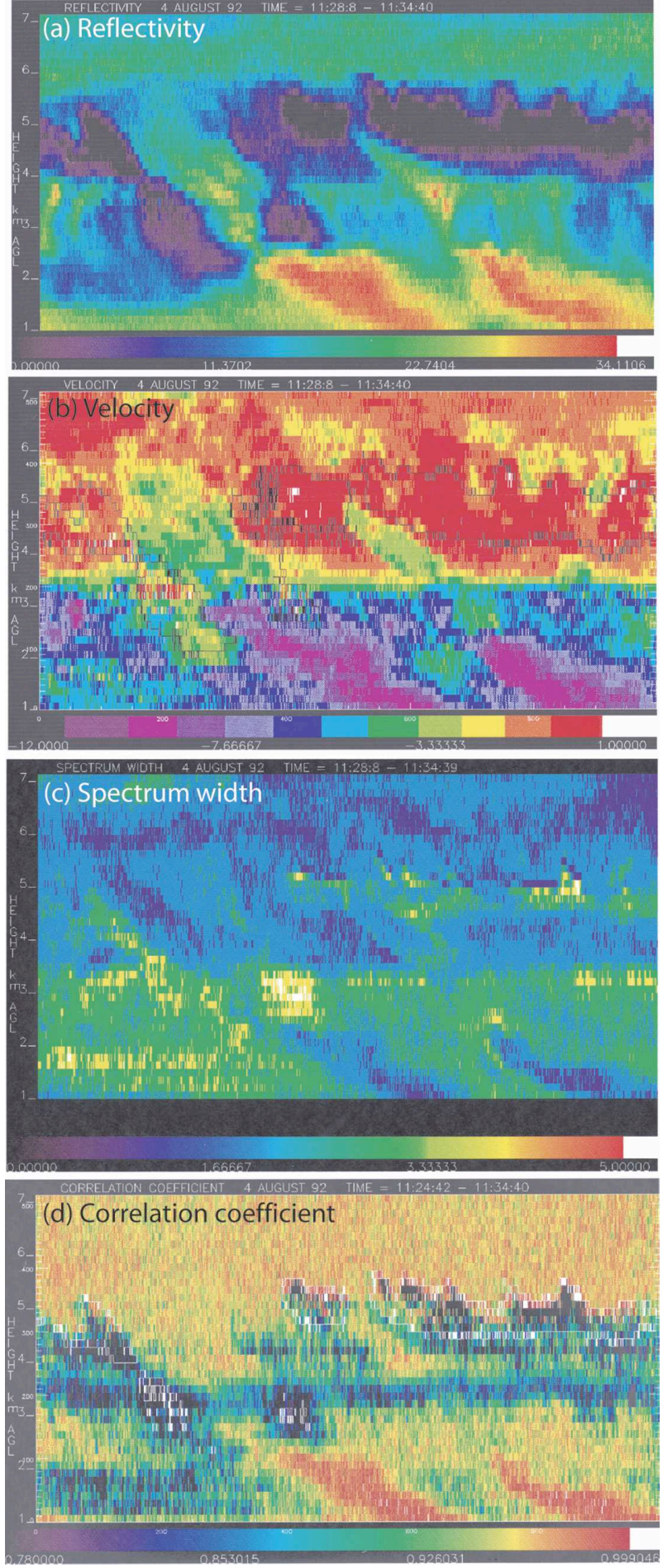

FIG. 8. Cimarron polarimetric radar data in vertically pointing mode, 1128:08-1134:40 UTC 4 Aug 1992. (a) Reflectivity (dBZ); (b) velocity $\left(\mathrm{m} \mathrm{s}^{-1}\right)$, (c) spectrum width $\left(\mathrm{m} \mathrm{s}^{-1}\right)$, and (d) correlation coefficient. Height ranges from 1 to $7 \mathrm{~km}$ AGL. as it moved through northern Utah. The front was characterized by a temperature drop $\left(8^{\circ} \mathrm{C}\right.$ in $\left.8 \mathrm{~min}\right)$, strong pressure rise ( $3 \mathrm{hPa}$ in $30 \mathrm{~min}$ ), and wind gusting over $40 \mathrm{~m} \mathrm{~s}^{-1}$ (Schultz and Trapp 2003). An off-duty IPEX forecaster who was in Big Cottonwood Canyon in the Wasatch Mountains reported virga and mammatus draped from a cumulonimbus anvil ahead of the front around 0100 UTC 15 February (J. Ladue 2000, 2006, personal communication). He reported, "The mammatus was not as distinct as I see [during severe weather in the central Great Plains of the United States. In this case, the mammatus consisted of] stringy virga extensions toward the ground without defined rounded surfaces." These observations of virga in association with mammatus are similar to those of Clarke (1962).

DOW2 was located $55 \mathrm{~km}$ north-northwest from Ladue's position. An RHI from 0104 UTC 15 February (Fig. 9a) shows the forward-sloping cloud with lobes of higher reflectivity underneath, about $1-2 \mathrm{~km}$ in horizontal scale. ${ }^{1}$ The corresponding radial-velocity field shows wind-speed minima at the bottoms of the largest lobes (Fig. 9b). Unfortunately, it was not obvious that the mammatus could be identified in plan position indicator (PPI) images from DOW2 so that the horizontal distribution of the mammatus could be determined.

Mobile Cross-Chain Loran Atmospheric Sounding System (M-CLASS) soundings were released from the two NSSL mobile laboratories (Rust et al. 1990): NSSL4 was located at Oasis on the west side of the Great Salt Lake and NSSL5 was located at OgdenHinckley Airport (OGD). The high vertical resolution (1 $\mathrm{s}$ or about $2-8 \mathrm{~m}$ ) available with the M-CLASS soundings provides detail about the environment in which the mammatus occurred. A sounding was released from NSSL4 at 2347 UTC 14 February, 15 min before the surface front passed, through the likely location of the mammatus. The profile was characterized by a dry-adiabatic layer below $680 \mathrm{hPa}$, an approximately moist-adiabatic layer above $660 \mathrm{hPa}$, and a superadiabatic layer $246 \mathrm{~m}(20.9 \mathrm{hPa})$ deep below the cloud (Fig. 10a). The lapse rate was $12.6^{\circ} \mathrm{C} \mathrm{km}^{-1}$ or a decrease in potential temperature of $0.8 \mathrm{~K}$ between 680.7 and $659.8 \mathrm{hPa}$ at temperatures of -2.0 to $-5.1^{\circ} \mathrm{C}$, respectively. Berg (1938, his Fig. 2) observed a superadiabatic layer under mammatus, and Wagner (1948) argued that such a superadiabatic layer was important to the formation of mammatus.

Nearly 90 min later, the sounding from NSSL5 at

\footnotetext{
${ }^{1}$ This cross section of radar reflectivity (Fig. 9a) morphologically resembles smoke plumes undergoing fumigation, where stable air within the cloud overrides unstable air below (e.g., Pasquill 1962, 181-182).
} 


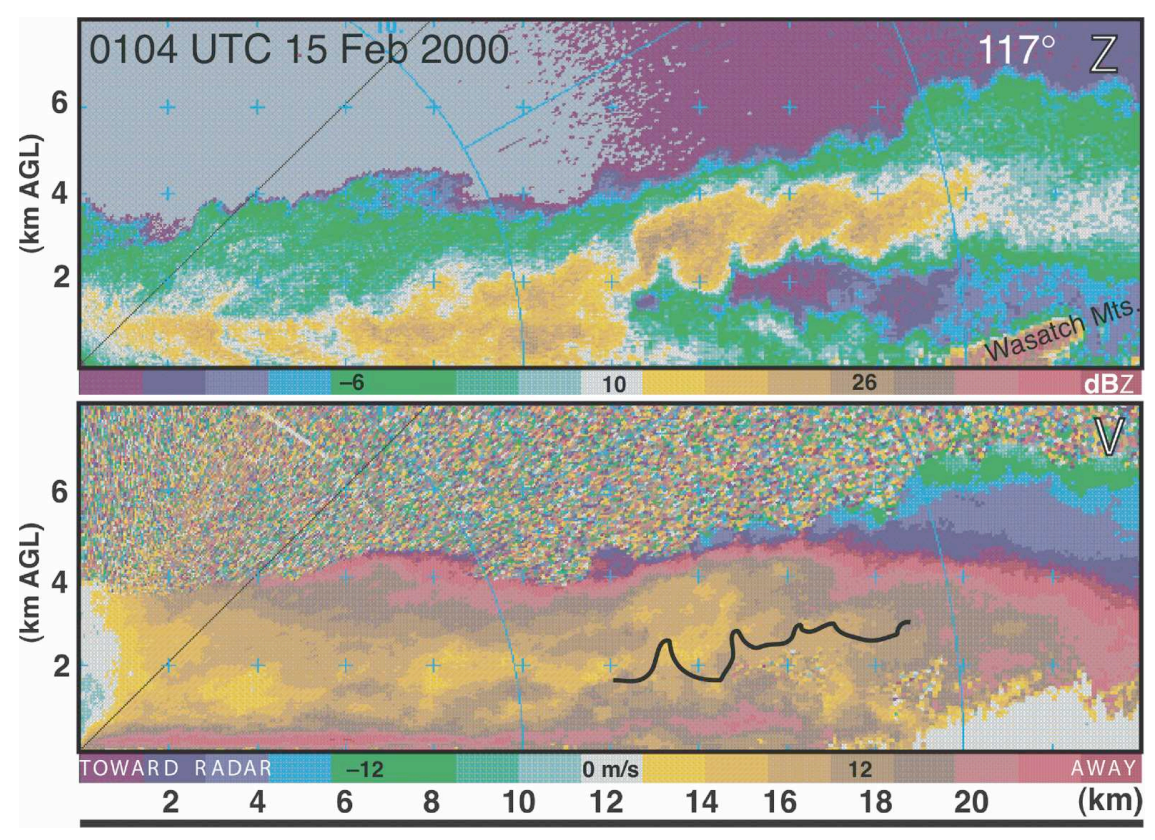

FIG. 9. RHIs from the Doppler on Wheels (DOW2) at 0104 UTC 15 Feb 2000 along the $117^{\circ}$ azimuth: (a) radar reflectivity factor $(\mathrm{dBZ})$; (b) radial velocity $\left(\mathrm{m} \mathrm{s}^{-1}\right)$. Solid black line in (b) represents approximate outline of mammatus in (a).

0115 UTC 15 February indicated cloud base was 2.97 $\mathrm{km}$ MSL and $-1.7^{\circ} \mathrm{C}$ (Fig. 10b). The cloud base from the sounding agreed with the height of the mammatus determined from the RHIs $(3.0 \mathrm{~km}$ MSL or $1.7 \mathrm{~km}$ AGL on Fig. 9a). This sounding also had a slight superadiabatic layer underneath cloud base (lapse rate of $\left.10.2^{\circ} \mathrm{C} \mathrm{km}^{-1}\right), 49 \mathrm{~m}$ thick $(4.4 \mathrm{hPa})$ with a temperature decrease of $0.5^{\circ} \mathrm{C}$ and a potential temperature decrease of only $0.02 \mathrm{~K}$, indicating the deeper superadiabatic layer observed earlier at NSSL4 had mostly stabilized. In the inset of Fig. 10b, several superadiabatic layers, separated by very stable layers, are seen below cloud base; this pattern is likely indicative of highly turbulent layers. The RHIs (e.g., Fig. 9a) and soundings (Fig. 10) indicate that the cloud deck was descending.

\section{e. Summary of observations of mammatus}

To summarize, the literature provides some information about the characteristics of mammatus clouds. Mammatus occur in association with a variety of cloud types: cumulonimbus, altocumulus, altostratus, stratocumulus, and cirrus. Mammatus have even been observed in contrails from jet aircraft and clouds of volcanic ash. The horizontal dimensions of individual mammatus lobes range from $250 \mathrm{~m}$ to $8 \mathrm{~km}$, with average dimensions based on the available observations of 1-3 km. Vertical extent below cloud base ranges from 0.3 to $1.1 \mathrm{~km}$, with most about $0.5 \mathrm{~km}$. Whereas some studies state the vertical and horizontal scales of motion within mammatus to be nearly equal, others have suggested or provided evidence that mammatus lobes may be linked to vertical motions of much greater depth, perhaps even extending from the top of the cirrus outflow anvil to the bottom cloud base of the mammatus lobes. Mammatus can appear in a local patch over a small section of cumulonimbus anvil or be spread out over hundreds of $\mathrm{km}$. The duration of a field of mammatus can range from 15 min to as much a few hours. The life cycle of an individual mammatus lobe is shorter, however, on the order of $10 \mathrm{~min}$.

Depending on the height of the anvil outflow [reported as low as $1.4 \mathrm{~km}$ by Hlad (1944) and as high as $8 \mathrm{~km}$ by Wang and Sassen (2006)] and the ambient stratification, mammatus may be composed of mostly liquid (e.g., Hlad 1944), mostly ice (e.g., Stith 1995; Kollias et al. 2005), or perhaps a combination of both. Mammatus in clouds of volcanic ash may challenge the notion whether moist processes are even required in some situations. Several studies have noted a negative correlation between radar reflectivity factor and vertical motion in mammatus fields, indicating that the biggest hydrometeors are in the downward-protruding lobes. Descending air motion in the core of the mammatus lobe is typically about $-3 \mathrm{~m} \mathrm{~s}^{-1}$, surrounded by about $+1 \mathrm{~m} \mathrm{~s}^{-1}$ of rising motion.

These observations, however, do not offer a consis- 
(a)
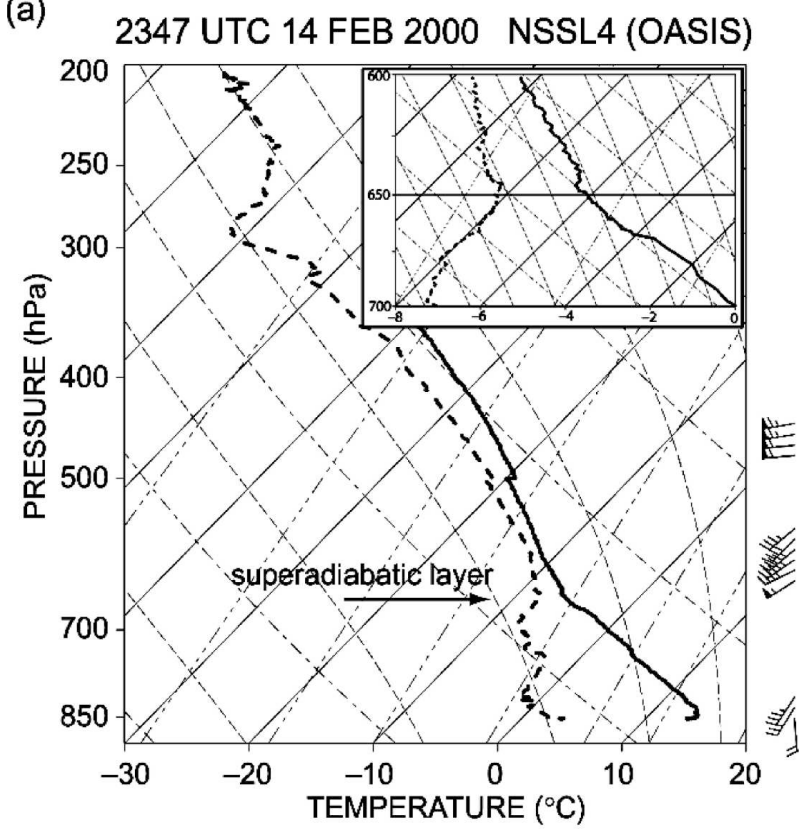

(b) 0115 UTC 15 FEB 2000 NSSL5 (OGDEN)

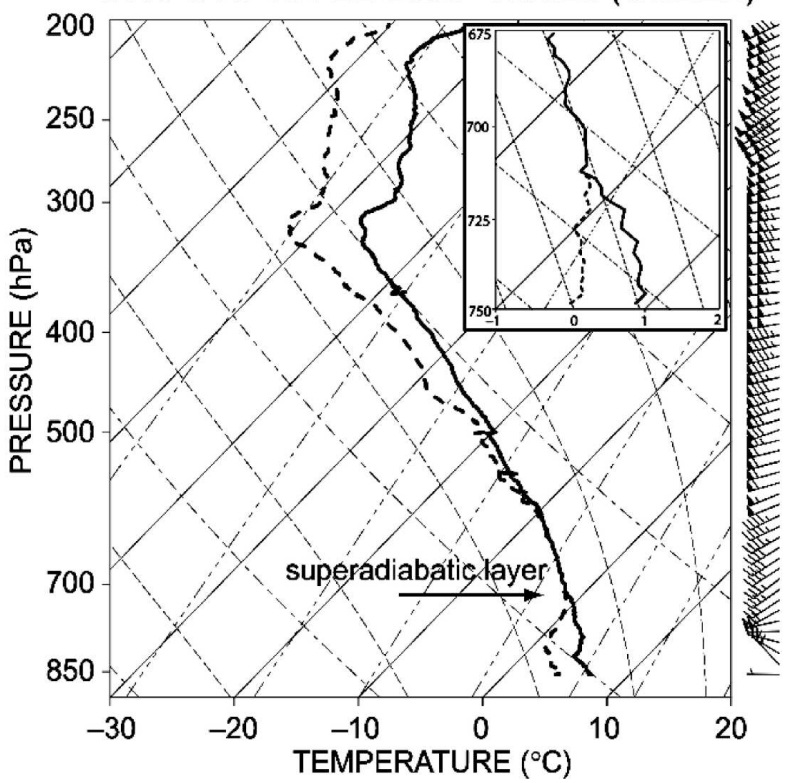

FIG. 10. Skew $T-\log p$ plot of observed soundings at (a) NSSL4 2347 UTC 14 Feb 2000 and (b) NSSL5 0115 UTC 15 Feb 2000. Temperature $\left({ }^{\circ} \mathrm{C}\right.$, solid lines), dewpoint temperature $\left({ }^{\circ} \mathrm{C}\right.$, dashed lines), and winds (one pennant, full barb, and half barb denote 25, 5 , and $2.5 \mathrm{~m} \mathrm{~s}^{-1}$, respectively). Insets are expanded areas of soundings showing details of the cloud base and superadiabatic lapse rates.

tent picture of mammatus in some very significant ways. First, because mammatus have been observed in different environments and with different hydrometeors, multiple formation mechanisms may be acting. Second, sometimes an inversion is observed at or below cloud base in association with or in proximity to the mammatus, whereas a subcloud superadiabatic layer is observed in other cases. Still other cases may possess both. Finally, aircraft penetrations through mammatus may be smooth or turbulent. Thus, there remains much to learn about the processes affecting mammatus. The remainder of this paper addresses these and other issues.

\section{Mechanisms for formation}

A variety of mechanisms have been proposed for mammatus formation. Unfortunately, the serendipitous and limited observations of mammatus often lack the necessary thermodynamic and microphysical data to assess their formation and evolution, let alone adequately describe their structure. Consequently, rigorous evaluation of these mechanisms can be difficult. In this section, hypothesized mechanisms for mammatus are reviewed and critically examined. Evidence supporting or refuting these mechanisms, where available, is presented.

Unless otherwise indicated, the theories discussed in this section pertain primarily to cumulonimbus anvil mammatus (e.g., Fig. 1a). A cumulonimbus anvil forms when the updraft of a cumulus cloud reaches its equilibrium level and spreads out. Because the recently risen air in the anvil is not likely to have the same temperature, moisture, and momentum as the surrounding environmental air, the base of the anvil is often characterized by a strong vertical temperature gradient (either an inversion or a superadiabatic layer), strong gradient in moisture, and strong wind shear. In this environment, cumulonimbus anvil mammatus form.

Some of the following mechanisms overlap. For example, several mechanisms destabilize the cloud base (e.g., the first three sections that follow). Such studies argue that the creation of a statically unstable layer is crucial for the formation of mammatus. Indeed, statically unstable layers exist in several of the recent soundings that sampled mammatus layers (e.g., Fig. 10 of this paper; Fig. 8 of Stith 1995; Fig. 8 of Winstead et al. 2001). Despite some overlap, the following processes are retained as separate discussions, in part because previous studies have presented them separately.

\section{a. Large-scale anvil subsidence}

Large-scale anvil subsidence was first proposed by Wagner (1948), Ludlam and Scorer (1953), and Scorer $(1958,1972)$. This mechanism posits that the dynamics of the thunderstorm anvil provide a large-scale environment favorable for the initiation of mammatus. 
When cloudy anvil air flows horizontally over a layer of unsaturated air, a vertical moisture gradient exists. Sinking of the cloud deck and the unsaturated air below occurs, perhaps because of the compensating downdrafts associated with the main thunderstorm updraft (e.g., Ludlam and Scorer 1953), the descent of hydrometeors through the cloud (e.g., Wagner 1948; Martner 1995; Platt et al. 2002), or the cloud deck having reached its level of neutral buoyancy. [Descending anvils have been described by Lilly (1988), Martner (1995), Platt et al. (2002), Knight et al. (2004), and Wang and Sassen (2006).] As the air sinks, the cloudy layer warms at the moist-adiabatic lapse rate, while the unsaturated air below warms at the dry-adiabatic lapse rate. The difference in lapse rates results in greater warming in the subcloud air than in the cloudy air and a consequent steepening of the local lapse rate at the cloudy-clear-air interface. Convective overturning at the base of the anvil may then result, in which the saturated air falls in drop-like formations resembling mammatus lobes (e.g., Ludlam and Scorer 1953).

Observational support for this mechanism comes from Imai (1957). Using a 3.2-cm radar in Japan, Imai (1957) documented a thunderstorm with a subsiding anvil and a horizontal cellular pattern of mammatus clouds. Reflectivity images (his Fig. 11) show an anvil underside with mammatus-like features remarkably similar to that presented more recently (e.g., Martner 1995; Winstead et al. 2001; section 2d of the present paper). The anvil descended from 11 to $8 \mathrm{~km}$ over about $3 \mathrm{~h}$. The anvil descent speed of $0.4 \mathrm{~m} \mathrm{~s}^{-1}$ was similar to the terminal velocity for frozen $0.7-\mathrm{mm}$ ice needles, suggesting some validity to Wagner's (1948) hypothesis. (The size and shape of the hydrometeors at the top of the anvil cannot be assumed to be the same as those at the bottom, however.)

Although a plausible mechanism, there are several problems with large-scale subsidence as the sole mechanism for mammatus production. First, some previous observations of mammatus do not show subsidence of the cloud base. For example, the 4 August 1992 event discussed in section $2 \mathrm{~d}(1)$ exhibited weak ascent in the region below the mammatus, which is consistent with the conceptual model of mesoscale ascent above the melting level within mesoscale convective systems (e.g., Houze et al. 1989). Second, care must be taken in interpreting some mammatus cases where a descending anvil is believed to occur. Specifically, if a mammatus event is observed on a sloped undersurface of a cloud deck from a time series of radar reflectivity from a vertically pointing radar [e.g., Martner 1995; Kollias et al. 2005; section $2 \mathrm{~d}(\mathrm{l})$ of the present paper], then deter- mining whether a horizontal cloud base descended over time or whether a sloped cloud base [e.g., Warner 1973; section $2 \mathrm{~d}(2)$ of the present paper] translated over the radar cannot be determined without additional information. Finally, separating the fall speed of the hydrometeors from the vertical air motions is not easy, thereby preventing a clean interpretation of the meaning of these radar-derived vertical motions. In any case, the data needed to adequately test the hypothesis that anvil subsidence produces an instability responsible for mammatus formation, even for a specific case, is lacking.

\section{b. Subcloud evaporation/sublimation}

Subcloud evaporation or sublimation is the most commonly cited mechanism to explain mammatus formation, originating from Troeger (1922), Letzmann (1930), Hlad (1944), Ludlam (1948), and Scorer (1958). Ice crystals, snow aggregates, liquid water droplets, or mixtures of these hydrometeors fall from cloud base into subsaturated air and begin to sublime and evaporate. Cooling just below cloud base provides the impetus for saturated descent in mammatus-like lobes. This process, if it occurs over a large portion of the cloud base, can result in a lowering of the anvil cloud base over time (see section 3a). At the point where the descending lobe is no longer buoyant with respect to the ambient air, the lobe, or edges of the lobe, may return upward and create a rounded shape to the mammatus cloud.

Three pieces of evidence support subcloud evaporation/sublimation as a viable hypothesis for mammatus formation. First, several radar-based studies imply that the decreasing particle size and the narrowing size distribution near the bottom of radar-observed mammatus lobes indicate evaporation/sublimation is occurring within the mammatus lobes (e.g., Martner 1995; Kollias et al. 2005; Wang and Sassen 2006). Aircraft penetrations by Heymsfield (1986) also found that evaporation was occurring underneath a cumulonimbus anvil in a region where mammatus was forming.

Second, Letzmann (1930) hypothesized that the cooling due to evaporation of water droplets below cloud base, in conjunction with the warming due to descent of the cumulonimbus anvil, may be responsible for the commonly observed inversion at the base of the mammatus (e.g., Clayton 1911; Hartmann 1920; Schneider 1920).

Finally, the prevalence of a subcloud dry layer in many soundings near mammatus (e.g., Clayton 1911; Schneider 1920; Berg 1938; Hlad 1944; Wagner 1948; Winstead et al. 2001; Wang and Sassen 2006; Fig. 10a of the present paper; K. M. Kanak and J. M. Straka, un- 
published research results) suggests evaporation near cloud base is likely. For example, soundings through mammatus sometimes show a superadiabatic layer underneath the mammatus (e.g., Fig. 2 in Berg 1938; Fig. 10 in the present paper). Superadiabatic layers in the free atmosphere can result from strong evaporation, cooling the air just below cloud base more quickly than turbulence can eliminate the instability. Hodge (1956) noted similar superadiabatic layers at the tops of clouds where evaporative cooling was occurring. Such superadiabatic layers are more common than perhaps previously recognized. For example, Slonaker et al. (1996) constructed a climatology of superadiabatic layers at least $50 \mathrm{hPa}$ above the surface in 73497 soundings from the U.S. Midwest for 1983-87. They found $60 \%$ of the soundings had at least one superadiabatic layer, although most of these layers were only a few degrees in magnitude and existed over a shallow depth. Slonaker et al. (1996, their Table 9) identified where these layers occurred relative to clouds and found that $7.5 \%$ of the layers with superadiabatic lapse rates existed below cloud base. Precipitation falling onto temperature sensors approaching clouds may also explain some subcloud superadiabatic lapse rates. Section 4.3 .2 of the Federal Meteorological Handbook 3 (http://www.ofcm. gov/fmh3/text/chapter4.htm) states that superadiabatic layers "shall be categorized as valid if the decrease in potential temperature in the layer does not exceed 1.0 $\mathrm{K}$. If the lapse rate exceeds this value, the temperature data in the layer are not realistic. Data shall be deleted if the potential temperature decreases by more than 1.0 $\mathrm{K}$ over any stratum or interval. If the temperature reverts back to the original trend, the data should be carefully examined to determine if the shift is real or erroneous. If the observer suspects it is erroneous those data shall be flagged as doubtful." In both cases in Fig. 10 , the superadiabatic layers are valid by these criteria.

Despite strong evidence in support of evaporative cooling as a mechanism for some mammatus, there are three reasons why it may not be operating in all cases. First, the presence of evaporation does not always produce mammatus (Heymsfield 1986). Second, Stith (1995) argued that, because the temperature inside a mammatus lobe was $0.7^{\circ} \mathrm{C}$ higher than that outside, evaporative cooling could not be responsible, at least at the mature stage of this one mammatus lobe. Expecting the inside of a mammatus lobe to be warmer or cooler does not appear to be a rigorous test for the evaporative cooling hypothesis, however. For example, initial inhomogeneities in evaporative cooling at cloud base may manifest themselves as the early stages of mammatus, drawing the cloudy air downward underneath the maxima of cooling. Once the mammatus lobes ma- ture and become large, evaporative cooling becomes greatest at the edge of the mammatus, not inside the mammatus. Thus, in the mature stage, we speculate that moist-adiabatic descent and warming may be occurring within the mammatus lobe, whereas evaporative cooling may be occurring along the edges where descent (and adiabatic warming) is less, also.

Third, Martner (1995), Winstead et al. (2001), and section $2 \mathrm{~d}(\mathrm{l})$ of the present paper documented reflectivity and velocity structures extending from the mammatus bases up to $1 \mathrm{~km}$ or so into the convective cloud. That the vertical velocities at heights above the mammatus bases were greater than those within the mammatus lobes suggests that evaporation at cloud base was not the main driving force for these downward motions. On the other hand, Platt et al. (2002) presented lidar data of tropical cirrus clouds with mammatus. Calculations of cooling rates based on their data yielded cooling to at least $1 \mathrm{~km}$ above cloud base. Thus, evaporative cooling may act on scales much deeper than just at the cloudy-clear-air interface.

\section{c. Melting}

Like sublimation and evaporation, cooling due to melting near cloud base may be responsible for mammatus formation. Knight et al. (2004) found that the descent of an anvil below the freezing level appeared to be associated with the formation of mammatus. They proposed a mechanism, first suggested by Findeisen (1940), that explains the formation of convective clouds beneath and within nimbostratus generated through the agency of the melting level. As falling precipitation melts, release of latent heat deepens the isothermal layer at $0^{\circ} \mathrm{C}$ (e.g., Findeisen 1940; Stewart 1984; Bosart and Sanders 1991; Kain et al. 2000), steepening the lapse rate underneath. Eventually, saturation is reached in the layer below the melting level and convection can result. If cloud base were to occur near the freezing level, the formation of mammatus is possible.

This hypothesis is supported by two other observations. First, like Knight et al. (2004), Imai (1957, his Fig. 15) showed the close association between mammatus and the location of the radar bright band where melting occurs (e.g., Byers and Coons 1947). Second, Table 1 shows that five of the eight $(63 \%)$ noncirrus mammatus events in the literature for which temperatures were available occurred at temperatures within a few degrees of freezing. This observation would appear to be rather strong evidence for the viability of this mechanism. On the other hand, not all mammatus, including cirrus mammatus, occur near the melting layer [e.g., section $2 \mathrm{~d}(1)]$, thus melting may not be the sole mechanism by which all mammatus form. 


\section{d. Local-scale hydrometeor fallout}

Local inhomogeneities in hydrometeor mass can lead to inhomogeneities in vertical air motion, which can lead to inhomogeneities in the descent of hydrometeors. When coupled with the hydrodynamic effects of frictional drag around the edge of such a precipitation shaft, the scale of the downdraft expands, and mammatus-like perturbations may result (Scorer 1958). Although anvils are observed to subside possibly due to this effect (section 3a), this fallout mechanism does not require thermodynamic instability, which is essential to some other proposed mechanisms for mammatus.

As hydrometeors descend in lobes, sublimation and evaporation occur, eventually limiting the mass of hydrometeors causing the descent, which may limit the depth of descent. Once the mammatus lobe forms, it also forms a baroclinic zone owing to temperature gradients from the sublimation/evaporation and mass gradients from the presence of hydrometeors. Around the lobe, shear and curvature vorticity are present. The curvature vorticity would lead to the upward motions around the lobes, providing the observed ascending return flow (e.g., Fig. 4).

Supporting evidence for this mechanism comes from three sources. First, some studies have shown that variations of reflectivity in mammatus are negatively correlated with Doppler vertical velocity variations (e.g., Martner 1995; Jo et al. 2003; Wang and Sassen 2006). Thus, the descent in mammatus would appear to be strongly related to the fall speeds of the hydrometeors. In addition, the magnitudes of the vertical motions at the bottom of the mammatus are often comparable to the terminal velocity of the constituent hydrometeors (e.g., Stith 1995). Other evidence suggests that a cloud layer may fall faster than its constituent hydrometeors (Clark and List 1971).

Second, Heymsfield (1986) used in situ measurements of a Colorado thunderstorm anvil and found that aggregation of hydrometeors was a likely process within anvils and that the maximum particle size should increase with distance downwind of the updraft core. For storms in which this is true, mammatus located adjacent or very near the updraft core may be made up of generally smaller particles. Heymsfield (1986) added that falling aggregates lower the anvil base and modify the relative humidity below cloud base. He also observed that the particle spectrum broadened toward cloud base where mammatus existed. The broad spectrum at cloud base may allow differential fallout speeds, which might be conducive to forming lobe structures through the mechanism described above.

Third, Stith (1995) found a warm anomaly inside de- scending mammatus lobes relative to the ambient air. Thus, if the air inside the mammatus lobe is not negatively buoyant due to temperature, the air must be negatively buoyant due to the mass of hydrometeors or through nonhydrostatic effects in order to be responsible for the observed descending motion inside mammatus lobes.

A weakness in the hydrometeor fallout mechanism is that vertical motions inside the mammatus lobes can be larger than the fall speeds of hydrometeors, especially when those are small ice crystals with slow fall speeds (e.g., Martner 1995; Jo et al. 2003). Thus, the size or composition (ice/water) of the hydrometeors cannot be primarily responsible for the mammatus, and some other dynamic effect must be occurring. Furthermore, if fallout were a feasible mechanism, all clouds might have mammatus.

\section{e. Cloud-base detrainment instability}

Emanuel (1981; 1994, 220-221) presented a mixing theory to explain mammatus called cloud-base detrainment instability (CDI). CDI is analogous to cloud-top entrainment instability (e.g., Deardorff 1980; Randall 1980), but applied at the anvil cloud base. CDI is similar to, but differs from, subcloud evaporation/sublimation (section 3b) and hydrometeor fallout (section 3d) in the following manner. In subcloud evaporation/sublimation and hydrometeor fallout, condensed water is introduced to the dry subcloud air by precipitation (Ludlam and Scorer 1953), whereas, for CDI, condensed water is introduced to the dry subcloud air by mixing (Emanuel 1981). CDI typically occurs under differential horizontal advection of cloudy air over clear air, as in the case of cumulonimbus anvils.

The condition for CDI is that the liquid-water static energy of the subcloud air be higher than that of the cloudy air. Consider a cloudy-clear-air interface with this stratification. If a parcel of cloudy air is mixed down into the subcloud air and all the liquid water is evaporated, the resulting air parcel becomes negatively buoyant and accelerates downward. Instability is optimized by a moderate level of relative humidity in the subcloud layer. If the subcloud environment is too moist, evaporation takes place too slowly to overcome adiabatic warming; if it is too dry, evaporative cooling of the hydrometeors quickly occurs and penetration of the thermal will not be very deep. Fernandez (1982) suggested that CDI may be responsible for local-scale initiation of downdrafts in tropical squall lines, although the scale of the downdrafts would need to be hundreds of meters, smaller than the typical scale of mammatus (e.g., Table 1) in order to be effective. Emanuel (1981) further hypothesized that CDI could 
proceed rapidly enough in cirrus clouds to generate mammatus-like perturbations.

CDI implies a steep lapse rate under the cloud and an inversion at cloud base (Emanuel 1981) as observed in numerous cases of mammatus (e.g., Clayton 1911; Hartmann 1920; Schneider 1920; our Fig. 10a). On the other hand, CDI does not explain why mammatus only appears locally on some regions of the anvil and not over the entire anvil region (e.g., Fig. 1a). CDI also fails to explain how the mixing initiates, which is required to obtain the instability. Perhaps a second mechanism, like Kelvin-Helmholtz instability, is required to mix the air before CDI can ensue. According to K. Emanuel (2005, personal communication), CDI is almost linear, and so its release is expected to occur spontaneously.

\section{f. Radiative effects}

Mammatus are observed most frequently in the afternoon and early evening (e.g., Osthoff 1906; Troeger 1922), perhaps due to adequate illumination of the underside of cumulonimbus clouds that can only occur when the sun angle is low. Although most cumulonimbus occur during this time because of daytime heating, the prevalence of mammatus late in the day may also suggest that radiative processes may play some role in mammatus formation. For example, after the initial turbulence in the anvil outflow is largely dissipated, a radiative-convective mixed layer may form (Lilly 1988). The cloud top is almost certain to be radiatively warmer than its upper environment (i.e., space), whereas the bottom is probably cooler than its radiative environment (i.e., ground surface). Under these conditions, the anvil cloud may act somewhat like a stratocumulus layer, except convection is driven on both top and bottom. Plank et al. (1955) also suggested longwave radiation from cloud top might destabilize the cloud layer and lead to instabilities at cloud top. If so, radiative processes could result in deep vertical motions within the anvil. In this scenario, the mammatus at cloud base may be the visible manifestation of the convection penetrating downward from the top of the cloud layer. Based on radiative-cooling estimates of Ackerman et al. (1988), Lilly (1988) estimated a characteristic vertical velocity scale for this downward convection of about $2 \mathrm{~m} \mathrm{~s}^{-1}$, small compared to the storm updraft, but quite similar to the vertical motions within mammatus lobes (Table 1).

Radiatively cooled thermals expand as they descend. Similarity theory shows that the diameter of such thermals expands at a rate of about $50 \%$ of the cloud depth (e.g., Rogers and Yau 1989, 54-55). Thus, a mammatus lobe diameter of $1-3 \mathrm{~km}$ corresponds to a depth of penetration of 2-6 km, which is a typical depth of the cloud anvil.

How does the rate of radiational cooling compare to that from evaporation/sublimation? Consider a hypothesis whereby mammatus is driven by the evaporation of $1 \mathrm{~g} \mathrm{~kg}^{-1}$ of liquid precipitation. Complete evaporation would correspond to $2.5 \mathrm{~K}$ of cooling, as calculated from $L_{v} w / c_{p}$, where $L_{v}$ is the latent heat of vaporization, $w$ is the liquid water content, and $c_{p}$ is the specific heat of air. Of course, evaporation is not instantaneous. Assuming the precipitate falls order $1 \mathrm{~m} \mathrm{~s}^{-1}$ into a dry layer with $60 \%$ relative humidity, evaporation is order $10 \% \mathrm{~km}^{-1}$ (Pruppacher and Klett 1997, p. 543). In other words, the evaporative cooling rate is order $1 \mathrm{~K}$ $\mathrm{h}^{-1}$. For snow, cooling should be of a similar order of magnitude. In contrast, cloud-top radiative cooling could be well in excess of $5 \mathrm{~K} \mathrm{~h}^{-1}$ (e.g., Garrett et al. 2005) and is in the right place (cloud top, not cloud base) to stimulate the observed deep penetrative downdrafts. Thus radiative cooling can have similar, if not greater, potential for forcing negatively buoyant thermals.

Furthermore, observations by Garrett et al. (2005) showed that cloud radiative heating in optically thick, tropical cloud anvils can be concentrated within $100 \mathrm{~m}$ of cloud base, because terrestrial longwave radiation cannot penetrate deep into optically thick clouds. Consequently, a layer near the lowest part of the cloud becomes destabilized (Garrett et al. 2006). This type of radiative destabilization is more consistent with observations that show descending lobes originating within the cloud near cloud base [e.g., Martner 1995; Winstead et al. 2001; section $2 \mathrm{~d}(1)$ of the present paper]. The necessary precondition for this destabilization to occur is that the cloud is sufficiently optically dense (either small particles or large water contents) to be nearly opaque to longwave radiation in the lowest $100 \mathrm{~m}$ or so. Specifically, to create longwave radiative contrasts, the absorption optical depth should be greater than unity, in which case the visible optical depth is greater than about 2 , sufficient to nearly obscure the direct radiation beam from sources behind the cloud. Because clouds of volcanic ash are moist and optically thick (Fig. 1b, section $4 \mathrm{~g}$ ), this condition is likely satisfied for these situations. This argument raises the question: are mammatus ever seen extending from optically thin clouds? If so, then alternative mechanisms, such as evaporation, are required to produce the mammatus because longwave radiation is likely not playing an important role. Indeed, Fig. 2d shows blue sky between the mammatus lobes indicating that mammatus can occur in the absence of thick clouds. Two caveats to the above observation need to be made. First, what the thickness of the 
cloud was at the time any hypothesized downward penetrating thermal was initiated through radiative cooling is unknown. Second, the cloud may be thinner around the mammatus because of the descent of cloudy air from around the downward-penetrating lobe and the recirculation of drier air upward.

\section{g. Gravity waves}

Gravity waves are ubiquitous in the atmosphere. As such, it is perhaps not surprising that they have been implicated as mechanisms for mammatus formation. Gravity waves excited as thunderstorm updrafts impinge on the tropopause can result in wave phenomena at upper levels (e.g., Hung et al. 1979; Balachandran 1980; Fovell et al. 1992; Alexander et al. 1995; Beres et al. 2002), or gravity waves can result from the imposition of thermal forcing in the midtroposphere (e.g., Yang and Houze 1995; Pandya and Durran 1996). Clarke (1962; discussed in section 2b), Gossard and Sweezy (1974), and Winstead et al. (2001) observed wavelike patterns in cases associated with mammatus and attributed them to gravity waves.

Similar to the surface pressure oscillations observed by Clarke (1962), Gossard and Sweezy (1974) observed waves with surface observations and a radar sounder at San Diego, California. Waves were evident from the sounder at 500-750 m AGL, with a spectacular display of mammatus at middle levels $(2-7 \mathrm{~km})$ throughout the observation period. These waves were associated with significant wind shear at $1-4 \mathrm{~km}$. The shear was strongest within and above a nearly dry-adiabatic layer, where the directional shear was nearly $180^{\circ}$. A nearly adiabatic layer existed, across which the significant speed shear was observed, as was the case for Clarke (1962). Gossard and Sweezy (1974) calculated a Richardson number less than 0.25 at $2 \mathrm{~km}$ AGL. Although KelvinHelmholtz instability may have been being released, Gossard and Sweezy (1974) interpreted their results in the context of gravity waves. Proximity soundings showed conditional instability above the shear layer so that shear-induced waves could have resulted in the release of conditional instability that could then have been manifest as mammatus clouds. The presence of the shear and a similar sounding do not always imply the presence of mammatus, however (e.g., Gossard and Sweezy 1974; Gossard 1975).

Winstead et al. (2001) identified wave patterns in a mammatus-bearing cloud with 4-7-km wavelength and vertical velocity minima of $-10 \mathrm{~m} \mathrm{~s}^{-1}$. Vertical velocity perturbations of similar scale were also found in the clear air below the anvil, indicative of downwardpropagating waves. The lines of mammatus were approximately oriented perpendicular to the mean wind direction, ${ }^{2}$ and the sounding through the mammatus possessed exceptionally strong shear across the cloud base (Winstead et al. 2001, their Fig. 7).

Yang and Houze (1995) and Pandya and Durran (1996) used two-dimensional idealized simulations of convective systems with $1-\mathrm{km}$ horizontal resolution to show gravity waves on the underside of the trailing stratiform regions. These gravity waves modulated the cloud base in a manner that looked like mammatus, although clearly of much larger scale. Ooyama's (2001) two-dimensional idealized simulation of a convective updraft impinging on a stable layer excited gravity waves in a spreading canopy. He described the horizontal rotation of cloud at the outer edge of the spreading canopy as mammatus-like protrusions, although there may be some debate about the exact nature of these protrusions. Indeed, still photos (Fig. 1a) and timelapse movies (D. Dowell 2005, personal communication) of cumulonimbus sometimes show mammatus forming at the leading edge of the spreading anvil.

As for some previous mechanisms (e.g., sections 3e, f), one argument that works against gravity waves being responsible for mammatus is why mammatus would occur on a localized section of cumulonimbus anvil when gravity waves would be traveling radially away from the updraft over a larger horizontal distance. Furthermore, the scale and lobed shape of the mammatus do not match the pattern of vertical motions in a gravity wave. For example, Kollias et al. (2005, their Fig. 1) showed gravity waves within the depth of the cloud, but they were at a much different scale than that of the mammatus. Gravity waves may organize mammatus lobes, as perhaps seen in Fig. 1a, but likely do not generate the mammatus themselves.

\section{h. Kelvin-Helmholtz instability}

Kelvin-Helmholtz instability can occur within a stably stratified fluid with strong vertical wind shear (e.g., Chandrasekhar 1961, his chapter 11). If the shear across the interface exceeds a critical Richardson number relative to the stratification, then distinctive KelvinHelmholtz waves can form. Although early researchers recognized that mammatus often occurred in conjunction with strong wind shear (e.g., Wegener 1909; Hartmann 1920; Troeger 1922), Berg (1938) was the first to

\footnotetext{
${ }^{2}$ There is a discrepancy between the text on p. 161 and the figure caption of Fig. 3 in Winstead et al. (2001) (N. Winstead 2005, personal communication). The text should read, "The dashed lines in Fig. 3 indicate an orientation approximately perpendicular to the mean wind direction, though other orientations may also be envisioned."
} 
suggest that mammatus may be a result of the release of Kelvin-Helmholtz instability.

Strong evidence for an association between the release of Kelvin-Helmholtz instability and mammatus clouds comes from radar observations of a tropical cumulonimbus anvil by Petre and Verlinde (2004). They observed Kelvin-Helmholtz waves that descended to cloud base, occurring at the same time as the formation of mammatus clouds observed by Jo et al. (2003) and Kollias et al. (2005). Therefore, in at least one case, wave-induced vertical motions inside clouds appear to be associated with mammatus clouds, perhaps the most convincing evidence published to date.

Despite this evidence for the association of mammatus with Kelvin-Helmholtz instability, several questions arise. First, why don't mammatus look more like the organized rows of Kelvin-Helmholtz billows? Second, why isn't the nonlinear wave-breaking stage (Fig. 2g) apparent more frequently? Perhaps such wave breaking is not visible because the billows are in-cloud and not visible. In the case presented in Fig. $2 \mathrm{~g}$, the mammatus could have been formed due to other mechanisms, but began to break once the mammatus extended into a region of stronger shear. Whether the shear resulted in the release of Kelvin-Helmholtz instability that caused the mammatus or the mammatus revealed the existence of the shear layer is not known for this case. Finally, Kelvin-Helmholtz instability requires a statically stable atmosphere, so mammatus forming in regions of static instability are not likely to be due to Kelvin-Helmholtz instability.

Finally, although some aircraft penetrations through mammatus have been turbulent (e.g., Hlad 1944), others have not been (e.g., Stith 1995). Doppler spectrum width measurements by Kollias et al. (2005) indicate that the mammatus is the most turbulent region of the cloud, whereas Winstead et al. (2001) found that the mammatus was not very turbulent at all, although the environment was quite turbulent. It may be that if Kelvin-Helmholtz instability were responsible for mammatus, the billows may only be developing and, thus, not have become turbulent with breaking waves. Consequently, care must be taken in attributing Kelvin-Helmholtz instability to mammatus.

\section{i. Rayleigh-Taylor instability}

Rayleigh-Taylor instability was proposed as a mechanism for mammatus by Agee (1975). This instability, as classically defined (e.g., Rayleigh 1883; Taylor 1950), occurs on the interface between two incompressible fluids when denser fluid lies overtop a less-dense fluid (e.g., Chandrasekhar 1961, his chapter 10; Sharp 1984). Because Rayleigh-Taylor instability is an inter- facial instability, it cannot be applied to continuously stratified atmospheric flows.

For the sake of argument, however, if RayleighTaylor instability were applicable to clouds, the cloud could be considered one fluid and the subsaturated air below cloud the other fluid. Simple calculations reveal the magnitude of the effect that would be required to produce Rayleigh-Taylor instability. Assuming density increases with height, the necessary criterion for Rayleigh-Taylor instability, a subsaturated atmosphere would have to have a lapse rate exceeding $32^{\circ} \mathrm{C} \mathrm{km}^{-1}$, the autoconvective lapse rate (Glickman 2000, p. 64). Such a lapse rate is hard to imagine in the free atmosphere. Alternatively, density may increase with height because of precipitation loading. For a saturated atmosphere with a lapse rate of $7^{\circ} \mathrm{C} \mathrm{km}^{-1}$, the hydrometeor mixing ratio (liquid and/or ice) would need to increase at a rate of $\sim 100 \mathrm{~g} \mathrm{~kg}^{-1} \mathrm{~km}^{-1}$. For a 10 -m-deep layer at cloud base, the hydrometeor mixing ratio need increase only about $1 \mathrm{~g} \mathrm{~kg}^{-1}$. Such a change in the hydrometeor mixing ratio is possible across a hydrometeor front, suggesting that Rayleigh-Taylor instability might be acting along the cloudy-clear-air interface, or across the interface of an ash cloud (see section $4 \mathrm{~g}$ ).

Any fluid that has density increasing with height, however, will be statically unstable (i.e., $N^{2}<0$, where $N$ is the Brunt-Väisälä frequency). Thus, even if an interfacial instability (and an interface) exists, buoyant instability of the entire layer exists. Indeed, Rayleigh (1883) showed that the interfacial instability is simply the limiting case of the layer depth going to zero (i.e., an infinitely thin transition between two fluids). As noted earlier, to invoke an explanation requiring a discontinuous fluid seems artificial in the context of clouds. Therefore, mammatus formation does not seem likely to be associated with Rayleigh-Taylor instability.

\section{j. Rayleigh-Bénard-like convection and the Schaefer and Day mechanism}

Mammatus have been referred to as "upside-down convection" with sinking cold-air plumes instead of rising warm-air plumes (e.g., Schlatter 1985), and has been hypothesized to occur because of cellular convection (e.g., Ludlam 1948; Schaefer and Day 1981). Specifically, Rayleigh-Bénard convection arises from the creation of static instability through the heating of the lower boundary (or cooling of an upper boundary) of an initially quiescent homogeneous fluid. In the case of mammatus, however, the geometry is reversed with the lower boundary (cloud base) cooled by differential adiabatic cooling due to vertical motion (section 3a), evaporation (section 3b), or mixing (section 3e). Because this cooling is not occurring on a flat boundary, 
Rayleigh-Bénard convection cannot be occurring in the strictest sense, so we say the convection is RayleighBénard-like convection and refer to the more general term cellular convection.

Schaefer and Day (1981, p. 136) proposed a mechanism for mammatus in which Rayleigh-Bénard-like convection plays a central role. They argue:

In a short time the cloudy air reaches the same temperature as the cloud-free air because of radiation and mixing. Because some of the cloudy air above is now at the same temperature, it is unstable because of the aggregate weight of the cloud droplets. However, because it has no nearby boundaries, the falling air divides into a polygonal array of downward-moving parcels of air called Bénard Cells. Because such downward movement must have upward compensation of cloud-free air, the undersurface of the cloud soon becomes a mass of pendules.

Whether the cloudy air and cloud-free air reach thermal equilibrium is debatable (e.g., Stith 1995). Certainly, soundings where mammatus are present (e.g., Fig. 10) can show strong temperature gradients across cloud base. Taken as a whole, Schaefer and Day's (1981) proposed mechanism seems weak and unsubstantiated.

\section{Discussion}

In sections 2 and 3, we discussed previous observations of mammatus and proposed mechanisms for their formation, respectively. In this section, other questions concerning the composition, character, size, and organization of mammatus are discussed.

\section{a. Are mammatus composed of ice crystals or liquid water droplets?}

Scorer (1958) argued that mammatus are more likely to be seen in snow showers because the reduction in visibility is greater than rain, similar to the arguments about whether virga was associated with melting snow or evaporating rain (i.e., Fraser and Bohren 1992, 1993; Sassen and Krueger 1993). Table 1 shows the temperature at which mammatus was observed for eight events where temperature could be determined. Except for one event [case I in Hlad (1944), where the temperature was about $+15^{\circ} \mathrm{C}$ ], temperatures were all very near or below freezing $\left(+1^{\circ}\right.$ to $\left.-25^{\circ} \mathrm{C}\right)$, suggesting that mammatus is often associated with at least some ice. Certainly, cirrus mammatus (section 2c) is composed entirely of ice crystals.

Microphysical observations inside mammatus, however, are inconsistent. Aircraft penetrations of mamma- tus in Hlad's (1944) case III showed that rain was heavy inside the mammatus. In contrast, Stith (1995) found aggregated ice particles with insignificant liquid water amounts inside mammatus. The mammatus in Martner's (1995) and our cases (e.g., Figs. 8 and 9a) occurred above the radar bright band, also suggesting ice was a component. Clough and Franks (1991) showed that the sublimation of snow and falling ice hydrometeors occurs more rapidly and over a shorter distance than liquid water, suggesting some preference for frozen hydrometeors in mammatus. Thus, mammatus are likely to be mostly ice, although some may occur with liquid water.

In the case of mammatus in jet contrails, liquid water contents are very low (about $1-10 \mathrm{mg} \mathrm{m}^{-3}$ ), so it is unlikely that precipitation-sized particles are involved. Observations of hydrometeors in contrails confirm relatively small particle sizes $(1-10 \mu \mathrm{m}$; Schröder et al. 2000), much smaller than precipitation-sized hydrometeors. Thus, mechanisms that require precipitation can likely be eliminated from consideration for mammatus in contrails.

\section{b. Why are mammatus generally smooth and laminar?}

Regardless of whether mammatus are composed of ice crystals or liquid water, why the edges of the mammatus usually have smooth laminar shapes remains an intriguing question. Emanuel (1981) attributed the smoothness of mammatus to mammatus lobes having undershot their equilibrium levels. At the leading edge of such lobes, a layer of strong static stability would be observed that might account for their laminar appearance. Stith (1995) observed a warm anomaly inside the mammatus of $0.7^{\circ} \mathrm{C}$, suggesting that the strong static stability at their leading edge helps maintain the integrity of the individual lobes in agreement with Emanuel's (1981) hypothesis.

Second, Ludlam (1980) hypothesized that, with a uniformly sized hydrometeor distribution, the precipitation falls at the same rate as the downdraft and holds together. Stith (1995) measured the fall speed of ice particles in mammatus being similar to the downdraft, supporting this hypothesis. Further support comes from the observation that the descent associated with mammatus is rarely as large as the fall speed of rain drops $\left(\sim 5 \mathrm{~m} \mathrm{~s}^{-1}\right)$ and that most observations of mammatus occur at temperatures near or colder than freezing (Table 1).

A third hypothesis (e.g., Scorer 1972; Schlatter 1985) is that a range in ice crystal sizes results in more rapid evaporation of the smallest ones first, mostly around the edges of the mammatus. With the larger crystals 
inside the mammatus lobe and the hydrometeor concentration small enough, there appears to be a somewhat opaque, but smooth, outline to the cloud. Thus, there is a lower limit to the size of a protuberance that will be visible. This contrasts to the cumulus turrets that form at the top of the cloud, with their large liquid water contents, small hydrometeors, and sharp, fractal edges. Thus, mammatus is not upside-down convection.

Convective overturning at the base of the anvil (section 3e) results in cloudy air being drawn into the clear air below cloud base, and clear air being drawn upward into the anvil cloud deck. This vertical entrainment process as part of mammatus formation (e.g., Scorer 1972) can explain why mammatus sometimes appear more lumpy and cauliflower-shaped. Sometimes mammatus may appear semitransparent with double outlines. Scorer (1972) attributes this to the edge of the hydrometeor fallout being ahead of the cold descending thermal plume. Evaporation of the hydrometeors adds this cooled air to the descending plume, but, because the hydrometeors are falling into more stable air, the shape of the descending plume is relatively smooth.

\section{c. What controls the spatial and temporal scales of mammatus?}

Most mammatus have a typical horizontal dimension of 1-3 km in diameter (Table 1). Several observations of much smaller mean diameters of less than $1 \mathrm{~km}$ are also possible (e.g., Clarke 1962; Warner 1973). Why mammatus seem to occur with this particular narrow range of scales is unknown. The mechanism(s) responsible for the mammatus likely plays a controlling factor in the resulting scale. For example, in section $3 \mathrm{f}$, a relationship between the size of negatively buoyant downdrafts from cloud-top cooling and the size of mammatus lobes can be derived. Clearly, a more comprehensive understanding of the mechanism(s) that produce mammatus is required in order to understand the factors affecting the size of the mammatus.

Another important clue to understanding mammatus is their temporal scale, which is on the order of $10 \mathrm{~min}$ (e.g., Warner 1973). Given that mammatus have a length scale of about $1 \mathrm{~km}$ and a velocity scale of about $1 \mathrm{~m} \mathrm{~s}^{-1}$, scaling arguments suggest a time scale of about $15 \mathrm{~min}$. This argument is independent of the processes that cause mammatus, but it introduces new questions such as what dictates the length scale (discussed above) and what dictates the velocity scale. Dictates on the velocity scale are likely related to the mechanism, which may be associated with the buoyancy of the individual mammatus lobes, for example.

An alternative estimate of the temporal scale can be derived from the buoyancy period $2 \pi / N$. For typical atmospheric stabilities, a period of about 10 min results. This value, although perhaps a coincidence, is highly dependent upon the choice of $N$. Specifically, for neutral layers $(N=0)$, the buoyancy period would go to infinity, indicating that gravity waves could not be responsible for the mammatus and some other mechanism must be implicated. If $N$ is found to affect the time scale of the mammatus, then mammatus being driven by buoyancy is a possibility. If not, then mechanisms not associated with buoyancy are required (e.g., precipitation mechanisms).

\section{d. What controls how mammatus are organized?}

In a field of mammatus, the individual mammatus lobes can be organized in several ways. Sometimes mammatus can be organized into lines (e.g., Figs. 1a and 2d,f). For example, Warner (1973, his Fig. 1) and Winstead et al. (2001, their Fig. 3) suggested linear organization in their cases. In contrast, Imai (1957, his Fig. 17) reported cellular mammatus in a dissipating Japanese thunderstorm. At other times, mammatus appear to have no organized pattern (Ludlam and Scorer 1953, p. 321; Figs. 2a,c,e of the present paper) and form in clusters of unequal-sized lobes.

Linear organization to the mammatus lobes suggests that a wavelike process may be responsible. The possible role of gravity waves has already been discussed in section 3g. Another process that can lead to linear organization is shear in the presence of static instability. Consider mammatus forming in a region with both unstable stratification and vertical wind shear. If the Richardson number is less than 0, mammatus may extend deep below cloud base, appear with a smooth leading edge, and align in rows parallel to the local shear vector. In this case, the bands align parallel to the local shear vector, as in horizontal convective rolls in the planetary boundary layer. This mechanism was first proposed by Jeffreys (1928), first explained by Kuo (1963), and demonstrated rigorously by Asai (1970a,b). In contrast, if the Richardson number is greater than zero but less than $\sim 0.25$, then Kelvin-Helmholtz instability could occur, and mammatus would align in rows perpendicular to the local shear vector, as shown by Asai (1970b) for horizontal convective rolls in shear. A spectrum of intermediate morphologies may exist, being a function of the relationship between buoyancy and shear.

Less organization to the mammatus lobes may suggest a form of cellular convection akin to RayleighBénard convection (section 3j). Although mammatus may occur through cellular convection, better under- 
standing is needed before the validity of this process can be assessed. Furthermore, a rigorous observational examination of this mechanism is lacking because horizontal maps of a field of mammatus lobes and their organization over time do not exist.

\section{e. What is the relationship between mammatus, stalactites, and virga?}

Pendulous extensions from the cloud base observed by radar bear remarkable similarity to mammatus. Plank et al. (1955) referred to them as precipitans; Atlas (1955), Douglas et al. (1957), Imai (1957), and Platt et al. (2002), among others, referred to them as stalactites. Atlas (1955) and Harris (1977) used the terms stalactites and mammatus interchangeably, and Imai (1957) said that stalactites are mammatus. They stated that these stalactites were associated with snow falling into dry air, evaporating, cooling, and overturning the subcloud air.

Harris (1977) presented theoretical models based on radar data to study the structures associated with the sublimation of ice particles at the base of clouds, particularly mammatus and stalactite structures. In contrast to other studies, he reported that the cloud layer ascended. He stated that mammatus could be generated by cellular motions at cloud top that can be $1.5 \mathrm{~km}$ deep and 600-900 $\mathrm{m}$ in horizontal spacing. In this case of the modulation of precipitation at cloud top, wind shear reduced the duration of the stalactites.

Virga is defined as streaks of rain or ice crystals that fall from a cloud but evaporate before reaching the ground, although there is some debate about whether virga is associated with evaporating rain or melting snow (i.e., Fraser and Bohren 1992, 1993; Sassen and Krueger 1993). Hlad (1944), Aufm Kampe and Weickmann (1957), and Clarke (1962) suggested that virga may be created when mammatus lobes "burst" open: Might the formation of virga from mammatus occur when an equilibrium level for the downwardaccelerating parcel no longer exists and the restoring force is not strong enough to recirculate the cloudy air upward? The relationship between mammatus and virga, if any, is unclear.

\section{f. What is the relationship between mammatus and reticular clouds?}

Another unusual cloud phenomenon is reticular clouds (Kanak and Straka 2002), which, like mammatus, are similarly not well understood. Reticular is an adjective defined as, "resembling a net; having veins, fibers, or lines crossing" (Webster's New Collegiate Dictionary, s.v. "reticulate"). In reticular features, the
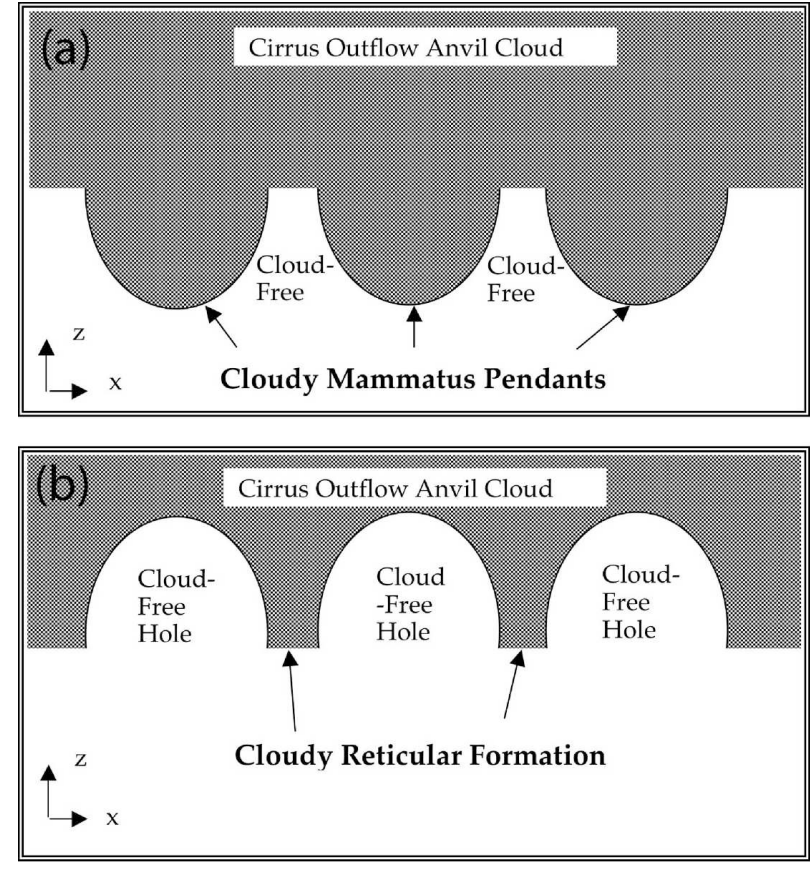

FIG. 11. Mammatus vs reticular clouds. Two-dimensional sketch of possible (a) mammatus and (b) reticular vertical cloud structure.

cloud peripheries outline a netlike pattern made visible by cloud condensation and have a cloud-free core (Fig. 11b). Ludlam and Scorer (1953) use reticular to contrast with the case of a typical convective cell in which upward motion in the center is coincident with cloudy air. In contrast to the downward protuberances of cloudy air in mammatus (Fig. 11a), reticular clouds have upward protuberances of clear air (Fig. 11b). Given that only one sounding has been collected in the vicinity of reticular clouds (Kanak and Straka 2002), we do not really know what the characteristic differences in the thermodynamic environment, if any, are between mammatus and reticular clouds.

\section{g. What are the properties of volcanic ash clouds that produce mammatus?}

As previously shown, mammatus can form in volcanic ash clouds. Only a few eruptions have documented such structures, however: Mount St. Helens on 18 May 1980 (e.g., Fig. 2h), Mount St. Augustine on 27-31 March 1986 (eruption pictures available online at http:// www.prattmuseum.org/kachemak/forces/volcano. html), and Mount Redoubt on 21 April 1990 (Fig. 1b). To understand possible mechanisms for such mammatus, measurements of the character of the ash clouds are required. A few research datasets have been described in the literature. For example, Hobbs et al. (1991, their 
Plate 1a) observed ash veils using airborne lidar in the ash plumes of the Redoubt eruptions in 1990. These ash veils were reminiscent of mammatus observed with radar (e.g., Plank et al. 1955; Imai 1957; Platt et al. 2002). In addition, the characteristics of pyrocumulus from in situ aircraft observations at Mount St. Helens have been described by Hobbs et al. (1981, 1982). They found large amounts of water (Hobbs et al. 1982), consistent with the large, wet, loosely aggregated ash that formed in the cloud [what Hobbs et al. (1981) termed volcanic hail]. Such results are consistent with the conclusion of Rose et al. (2003) who found that the majority of the particle mass from the Hekla, Iceland, 26-27 February 2000 eruption was ice nucleated on the surface of ash particles.

Remote sensing has shown that ice is an important component of volcanic clouds (Rose et al. 2004), but amounts vary markedly. Ice, which is thought to coat ash nuclei, dominates some volcanic clouds, as in the 19 September 1994 Rabaul Caldera eruption, Papua New Guinea (Rose et al. 1995) and the 2000 Hekla (Rose et al. 2003) eruptions. In contrast, in cases like the 17 September 1992 Mount Spurr eruption (Rose et al. 2001) and the 19 February 2001 eruption of Cleveland Volcano, Alaska (Gu et al. 2005), ash seems to dominate over ice during most of the life of the volcanic cloud. Finally, neither ice nor ash dominates in other volcanic clouds, such as those from the 15 June 1991 eruption of Mount Pinatubo, Luzon, Philippines (Guo et al. 2004) and March-April 1982 eruptions of El Chichón (Schneider et al. 1999). Once in the atmosphere, the mass of ice in volcanic clouds declines quickly, especially in the dry stratosphere. In the Hekla eruption, the total mass of ice decreased because of sublimation by an order of magnitude within $24 \mathrm{~h}(2 \mathrm{Tg}$ to $<0.2 \mathrm{Tg}$; Rose et al. 2003). A. Durant (2006, unpublished manuscript) has shown that, in the early stages of the September 1992 Spurr cloud, ice must have been abundant with at least $0.2 \mathrm{~g} \mathrm{~kg}^{-1}$ in the cloud $3.7 \mathrm{~h}$ after emplacement at $-62^{\circ} \mathrm{C}$ and $191 \mathrm{hPa}$. After only a few hours, the same Spurr cloud contained mainly ash, apparently also because of rapid sublimation (Rose et al. 2001). Overall, the role of ice must be very important in all volcanic clouds, although some clouds dry markedly within hours (Rose et al. 2004).

Given the abundant ice often found in volcanic clouds, the role of subcloud sublimation could be quite important to mammatus formation. Indeed, soundings taken near the eruptions discussed above (Mount St. Helens, Mount St. Augustine, and Redoubt) all possess dry subcloud layers (not shown), similar to soundings near cumulonimbus mammatus (e.g., Clayton 1911; Schneider 1920; Berg 1938; Hlad 1944; Wagner 1948;
Winstead et al. 2001; Wang and Sassen 2006; Kanak and Straka 2006; Fig. 10a of the present paper). Therefore, given the varying amounts of ice versus ash, the relative importance of sublimation versus particulate loading and fallout in creating mammatus in volcanic clouds remains unclear.

\section{Conclusions}

Serendipity has long been recognized as a driving factor in the advancement of science (e.g., Blanchard 1996, and references within). Nearly all observations of mammatus to date have resulted from serendipitous encounters with these clouds. Even idealized modeling simulations specifically designed to address mammatus have not been performed. This article presents a review of previous studies of mammatus, performs a critical analysis of proposed mechanisms, and raises additional unanswered questions about mammatus. Clearly, there is much that remains to be learned. Below we highlight just a few issues from this paper.

Most previous studies in the literature (especially the latter half of the twentieth century) discussed cumulonimbus anvil mammatus. Although cumulonimbus anvil mammatus is perhaps the most photogenic and impressive of the mammatus displays, mammatus can form in cirrus, cirrocumulus, altocumulus, altostratus, stratocumulus, contrails, and volcanic ash clouds.

Nearly all the observations of mammatus described in this paper are snapshots of just a few lobes at bestno studies have mapped out the horizontal distribution of the mammatus field, describing the evolution of mammatus over time. Observations of the environment before their formation and after their dissipation are not available. Yet, like other atmospheric phenomena, mammatus likely proceeds through some life cycle, which remains uncaptured with our current observations and models. For example, whereas some have hypothesized that mammatus may evolve into virga, many other observations show that this does not occur. Nevertheless, no study has carefully examined the evolution of a mammatus field. Could the existing observations reviewed in this paper be better put into context if they were placed within a mammatus lifecycle conceptual model? Modeling experiments would seem to be required to offer testable hypotheses in this regard.

Many mechanisms have been proposed in the previous literature and are summarized in section 3. Some of these mechanisms cannot be acting at the same time. For example, gravity waves and Kelvin-Helmholtz instability require stable stratification; thus, several observations pointing to the importance of statically un- 
stable layers tends to diminish the possible importance of these mechanisms. As another example, linear organization perpendicular to the shear vector supports Kelvin-Helmholtz instability, whereas linear organization parallel to the shear vector supports static instability, and organization radially from a heat source (i.e., a cumulonimbus cloud) supports gravity waves. Significantly, the observed variety of mammatus may indicate that more than one mechanism is responsible.

Proposed mammatus mechanisms must be able to explain the following observed characteristics of mammatus. First, the lifetime of a mammatus lobe is about $10 \mathrm{~min}$, although few quantitative observations of this lifetime exist. Second, the size of mammatus lobes is typically $1-3 \mathrm{~km}$. Third, the temperature of the cloud base relative to the surface temperature can be used to ascertain the role of radiative processes on the underside of the cloud. Specifically, if mammatus are ever observed with cloud-base temperature close to the surface temperature, then strong radiative-heating gradients near cloud base probably are not responsible for the mammatus. Fourth, the optical thickness of the clouds may also have some relevance in distinguishing between different mechanisms. For example, if mammatus is observed in optically thin clouds, radiative effects are probably negligible. Fifth, the temperature at cloud base can also be used to ascertain the relevance of evaporative cooling. The magnitude of cooling is tightly constrained by the saturation mixing ratio, which decreases exponentially with temperature. Sixth, the cloud-top brightness temperature from satellite relative to that of the atmosphere above provides a constraint on the amount of radiative cooling at cloud top. Seventh, if mammatus are merely a manifestation of upside-down convection, then a description is needed of why cumulus turrets differ in appearance from mammatus lobes. Last, observations of the temperature at which mammatus occur, along with hydrometeor composition inside mammatus lobes, could provide the critical observations to discriminate among several of the proposed mechanisms.

For example, cirrus mammatus are highly constrained on several levels. Because they exist at cold temperatures, the capacity for condensation/evaporation to affect local temperature is small, eliminating most of the latent-heat based mechanisms from consideration. In addition, given the small hydrometeor size in cirrus, fall speeds do not approach several $\mathrm{m} \mathrm{s}^{-1}$, eliminating the fallout mechanism. Wang and Sassen (2006) found that wind shears were relatively weak across the cloud bases of 25 cases of cirrus mammatus, eliminating shear instabilities. Thus, remaining viable mechanisms include radiative effects and gravity waves.
Several studies have shown convincing evidence that mammatus may be more than just appendages hanging down from cloud base. These appendages are the visible manifestations of motions inside the cloud, motions that may reach to the cloud top. What are the processes that are associated with the deep circulations present in mammatus? What role do mammatus serve in the atmosphere? What balance are they trying to restore?

To address these issues, additional specialized measurements of mammatus are needed. One way to obtain such measurements would be to organize a mammatus field program (may we suggest the name MAMMEX?), arguing that mammatus are the visible manifestation of poorly understood processes, like entrainment or microphysical effects. Alternatively, during field operations already occurring on different phenomena, collecting data on mammatus serendipitously as part of that larger research effort may be possible. Hopefully, datasets can be collected that provide complete microphysical, thermodynamic, and dynamic documentation of such mammatus. In particular, observations of the premammatus environment, hydrometeor type and concentration, thermodynamic measurements of the environment and the mammatus lobes, horizontal distribution of mammatus lobes, and evolution of the field of mammatus would be helpful to answer some of the questions in this paper.

Modeling studies of clouds using a hierarchy of models with increasing complexity from two-dimensional idealized models to three-dimensional real-data simulations could be performed to examine the structure and evolution of mammatus. Surprisingly, no modeling studies designed specifically to investigate mammatus exist. This deficiency could be attributable to two reasons. First, resolution needs to be quite high because mammatus have a typical spatial scale of about $1 \mathrm{~km}$. Thus, grid spacings on the order of $100 \mathrm{~m}$ are required. For example, Grabowski et al. (1998) found mammatus-like circulations in a two-dimensional cloud-model simulation with a horizontal grid spacing of $200 \mathrm{~m}$, but not in one with $2-\mathrm{km}$ grid spacing. Second, most idealized cloud simulations often use very moist soundings, not the dry subcloud air typically found in environments favoring mammatus. Well-designed numerical experiments could explore the sensitivities of the mammatus formation and structure to the thermodynamic and cloud microphysical conditions. By suggesting these experiments, we hope to inspire others to begin to think about the interesting scientific questions about mammatus needing to be explored.

Although mammatus clouds may not pose any significant weather threat, except perhaps for turbulence affecting aviation, their photogenic characteristics and 
their very occurrence raises many interesting scientific questions that challenge our conventional views of clouds and hydrometeors. As our review has shown, further studies of mammatus could help provide insights into the turbulent, microphysical, and dynamical processes occurring at the base of clouds. Mammatus also may give us additional information about anvil dynamics in cumulonimbus clouds. Because a dedicated field program to take measurements of mammatus may be a while in coming, serendipitous observations of mammatus during field programs, as in the past, as well as numerical modeling experimentation, may provide the key pieces of evidence to accept or refute some of the issues discussed in this paper.

Acknowledgments. We have benefited considerably from discussions with and comments from Ernest Agee, Will Cantrell, Charles Doswell, Larry Dunn, Kerry Emanuel, Frédéric Fabry, Robert Fovell, John Horel, Charles Knight, Alex Kostinski, Steven Krueger, James Ladue, Steve Nesbitt, William Rose, Richard Rotunno, Jason Shafer, Raymond Shaw, and Edward Zipser. Jeff Stith and two anonymous reviewers provided comments that improved the manuscript. A comprehensive search of the literature by Katherine Day, formerly of the NOAA Library in Boulder, was helpful in identifying articles that our initial survey did not discover. Photos of mammatus other than those by the authors are published with the permission of Charles Doswell (Figs. 1a and 2d), James Steenburgh (Fig. 2a), Vickie Doswell (Fig. 2b), and Montie Orgill (Fig. 2h). Figure $1 \mathrm{~b}$ was taken by R. J. Clucas, and is in the public domain. Thanks to Brooks Martner for providing Fig. 3, Ken Sassen for providing Figs. 5 and 7, and Likun Wang for providing Fig. 6. Thanks to David Dowell for sharing his time-lapse movies of mammatus clouds. Much of the work on the IPEX case in section 2d(2), and the early work on this manuscript, was performed during fall 2002 while Schultz was visiting the Department of Meteorology at the University of Utah; their support is gratefully acknowledged. Funding for Schultz and Kanak was provided by NOAA/Office of Oceanic and Atmospheric Research under NOAAUniversity of Oklahoma Cooperative Agreement NA17RJ1227, Department of Commerce. Funding was also provided for Kanak by NSF Grant ATM-0135510 and for Straka by NSF Grant ATM-0340639.

\section{REFERENCES}

Ackerman, T. P., K.-N. Liou, F. P. J. Valero, and L. Pfister, 1988: Heating rates in tropical anvils. J. Atmos. Sci., 45, 1606-1623.

Agee, E. M., 1975: Some inferences of eddy viscosity associated with instabilities in the atmosphere. J. Atmos. Sci., 32, 642-646.
Alexander, M. J., J. R. Holton, and D. R. Durran, 1995: The gravity wave response above deep convection in a squall line simulation. J. Atmos. Sci., 52, 2212-2226.

Asai, T., 1970a: Three-dimensional features of thermal convection in a plane Couette flow. J. Meteor. Soc. Japan, 48, 18-29.

_ 1970b: Stability of a plane parallel flow with variable vertical shear and unstable stratification. J. Meteor. Soc. Japan, 48, 129-139.

Atlas, D., 1955: The origin of "stalactites" in precipitation echoes. Proc. Fifth Radar Weather Conf., Asbury Park, NJ, U.S. Army Signal Corps, 321-326.

Aufm Kampe, H. J., and H. K. Weickmann, 1957: Physics of clouds. Meteorological Research Reviews: Summaries of Progress from 1951 to 1955, Meteor. Monogr., No. 18, Amer. Meteor. Soc., 182-225.

Balachandran, N. K., 1980: Gravity waves from thunderstorms. Mon. Wea. Rev., 108, 804-816.

Bauman, G., 1927: Mammato-Formation an Cirren (Mammatus formation on cirrus). Meteor. Z., 44, 420.

Beres, J. H., M. J. Alexander, and J. R. Holton, 2002: Effects of tropospheric wind shear on the spectrum of convectively generated gravity waves. J. Atmos. Sci., 59, 1805-1824.

Berg, H., 1938: Mammatusbildungen (Mammatus developments). Meteor. Z., 55, 283-287.

Berry, F. A., Jr., E. Bollay, and N. R. Beers, 1945: Handbook of Meteorology. McGraw-Hill, 1068 pp.

Blanchard, D. C., 1996: Serendipity, scientific discovery, and Project Cirrus. Bull. Amer. Meteor. Soc., 77, 1279-1286.

Bosart, L. F., and F. Sanders, 1991: An early-season coastal storm: Conceptual success and model failure. Mon. Wea. Rev., 119, 2831-2851.

Byers, H. R., and R. D. Coons, 1947: The "bright line" in radar cloud echoes and its probable explanation. J. Meteor., 4, 7581.

Chandrasekhar, S., 1961: Hydrodynamic and Hydromagnetic Stability. Oxford University Press, $654 \mathrm{pp}$

Clark, T. L., and R. List, 1971: Dynamics of a falling particle zone. J. Atmos. Sci., 28, 718-727.

Clarke, R. H., 1962: Pressure oscillations and fallout downdraughts. Quart. J. Roy. Meteor. Soc., 88, 459-469.

Clayton, H. H., 1911: A study of clouds with data from kites. Annal. Astron. Observatory Harvard Coll., 68, 170-192.

Clough, S. A., and R. A. A. Franks, 1991: The evaporation of frontal and other stratiform precipitation. Quart. J. Roy. Meteor. Soc., 117, 1057-1080.

Deardorff, J. W., 1980: Cloud top entrainment instability. J. Atmos. Sci., 37, 131-147.

Douglas, R. H., K. L. S. Gunn, and J. S. Marshall, 1957: Pattern in the vertical of snow generation. J. Meteor., 14, 95-114.

Emanuel, K. A., 1981: A similarity theory for unsaturated downdrafts within clouds. J. Atmos. Sci., 38, 1541-1557.

, 1994: Atmospheric Convection. Oxford University Press, 580 pp.

Fernandez, W., 1982: A review of downdrafts at the rear of tropical squall lines. Bull. Amer. Meteor. Soc., 63, 1285-1293.

Findeisen, W., 1940: Die Entstehung der $0^{\circ}$-Isothermie und die Fraktocumulus-Bildung unter Nimbostratus (The origin of $0^{\circ} \mathrm{C}$ isothermal layers and of fractocumulus beneath nimbostratus). Meteor. Z., 57, 49-54.

Fovell, R., D. Durran, and J. R. Holton, 1992: Numerical simulations of convectively generated stratospheric gravity waves. $J$. Atmos. Sci., 49, 1427-1442. 
Fraser, A. B., and C. F. Bohren, 1992: Is virga rain that evaporates before reaching the ground? Mon. Wea. Rev., 120,1565-1571.

— Mon. Wea. Rev., 121, 2429-2430.

Garrett, T. J., and Coauthors, 2005: Evolution of a Florida cirrus anvil. J. Atmos. Sci., 62, 2352-2372.

_- M. A. Zulauf, and S. K. Krueger, 2006: Effects of cirrus near the troposphere on anvil cirrus dynamics. Geophys. Res. Lett., 33, L17804, doi:10.1029/2006GL027071.

Gedzelman, S. D., 1989: Cloud classification before Luke Howard. Bull. Amer. Meteor. Soc., 70, 381-395.

Glickman, T. S., Ed., 2000: Glossary of Meteorology. 2d ed. Amer. Meteor. Soc., 855 pp.

Gordon, B. A., 1995: Structure of precipitation fields in the stratiform region of mesoscale convective systems as observed by polarimetric radar. M.S. thesis, School of Meteorology, University of Oklahoma, $104 \mathrm{pp}$. [Available from School of Meteorology, University of Oklahoma, 100 East Boyd St., Suite 1310, Norman, OK 73019.]

— D. S. Zrnić, and J. Straka, 1995: Observations of mammata with polarimetric Doppler radar. Preprints, 27th Conf. on Radar Meteorology, Vail, CO, Amer. Meteor. Soc., 461-463.

Gossard, E. E., 1975: Reply. J. Atmos. Sci., 32, 639-642.

— , and W. B. Sweezy, 1974: Dispersion and spectra of gravity waves in the atmosphere. J. Atmos. Sci., 31, 1540-1548.

Grabowski, W. W., X. Wu, M. W. Moncrieff, and W. D. Hall, 1998: Cloud-resolving modeling of cloud systems during Phase III of GATE. Part II: Effects of resolution and the third spatial dimension. J. Atmos. Sci., 55, 3264-3282.

Gu, Y., W. I. Rose, D. J. Schneider, G. J. S. Bluth, and I. M. Watson, 2005: Advantageous GOES IR results for ash mapping at high latitudes: Cleveland eruptions 2001. Geophys. Res. Lett., 32, L02305, doi: 10.1029/2004GL021651.

Guo, S., W. I. Rose, G. J. S. Bluth, and I. M. Watson, 2004: Particles in the great Pinatubo volcanic cloud of June 1991: The role of ice. Geochem. Geophys. Geosyst., 5, Q05003, doi:10.1029/2003GC000655.

Harris, F. I., 1977: The effects of evaporation at the base of ice precipitation layers: Theory and radar observations. J. Atmos. Sci., 34, 651-672.

Hartmann, W., 1920: Über die Entstehung von Mamato-Formen (About the origin of mammatusforms). Meteor. Z., 37, 216220

Heymsfield, A. J., 1986: Ice particle evolution in the anvil of a severe thunderstorm during CCOPE. J. Atmos. Sci., 43, 24632478.

Hlad, C. J., Jr., 1944: Stability-tendency and mammatocumulus clouds. Bull. Amer. Meteor. Soc., 25, 327-331.

Hobbs, P. V., L. F. Radke, M. W. Eltgroth, and D. A. Hegg, 1981: Airborne studies of the emissions from the volcanic eruptions of Mount St. Helens. Science, 211, 816-818.

— , J. P. Tuell, D. A. Hegg, L. F. Radke, and M. W. Eltgroth, 1982: Particles and gases in the emissions from the 1980-1981 volcanic eruptions of Mt. St. Helens. J. Geophys. Res., 87, 11 062-11 086.

, L. F. Radke, J. H. Lyons, R. J. Ferek, D. J. Coffman, and T. J. Casadevall, 1991: Airborne measurements of particle and gas emissions from the 1990 volcanic eruptions of Mount Redoubt. J. Geophys. Res., 96, $18735-18752$.

Hodge, M. W., 1956: Superadiabatic lapse rates of temperature in radiosonde observations. Mon. Wea. Rev., 84, 103-106.

Houze, R. A., Jr., S. A. Rutledge, M. I. Biggerstaff, and B. F. Smull, 1989: Interpretation of Doppler weather radar dis- plays of midlatitude mesoscale convective systems. Bull. Amer. Meteor. Soc., 70, 608-619.

Hung, R. J., T. Phan, and R. E. Smith, 1979: Case studies of gravity waves associated with isolated tornadic storms on 13 January 1976. J. Appl. Meteor., 18, 460-466.

Imai, I., 1957: Radar study of a dissipating thunderstorm. Pap. Meteor. Geophys., 8, 81-97.

Jeffreys, H., 1928: Some cases of instability in fluid motion. Proc. Roy. Soc. London, 118A, 195-208.

Jo, I., B. A. Albrecht, and P. Kollias, 2003: 94-GHz Doppler radar observations of mammatus in tropical anvils during CRYSTAL-FACE. Preprints, 31st Int. Conf. on Radar Meteorology, Seattle, WA, Amer. Meteor. Soc., 197-199.

Kain, J. S., S. M. Goss, and M. E. Baldwin, 2000: The melting effect as a factor in precipitation-type forecasting. Wea. Forecasting, 15, 700-714.

Kanak, K. M., and J. M. Straka, 2002: An unusual reticular cloud formation. Mon. Wea. Rev., 130, 416-421.

—, and - 2006: An idealized numerical simulation of mammatus-like clouds. Atmos. Sci. Lett., 7, 2-8.

Knight, C. A., L. J. Miller, and W. D. Hall, 2004: Deep convection and "first echoes" within anvil precipitation. Mon. Wea. Rev., 132, 1877-1890.

Kollias, P., I. Jo, and B. A. Albrecht, 2005: High-resolution observations of mammatus in tropical anvils. Mon. Wea. Rev., 133, 2105-2112.

Kuo, H. L., 1963: Perturbations of plane Couette flow in stratified fluid and origin of cloud streets. Phys. Fluids, 6, 195-211.

Letzmann, J., 1930: Cumulus-Pulsationen (Cumulus pulsations). Meteor. Z., 47, 236-238.

Ley, W. C., 1894: Cloudland. Edward Stanford, 208 pp.

Lilly, D. K., 1988: Cirrus outflow dynamics. J. Atmos. Sci., 45, 1594-1605.

Ludlam, F. H., 1948: The forms of ice clouds. Quart. J. Roy. Meteor. Soc., 74, 39-56.

- 1980: Clouds and Storms, the Behavior of Water in the Atmosphere. Pennsylvania State University Press, $405 \mathrm{pp}$.

- and R. S. Scorer, 1953: Convection in the atmosphere. Quart. J. Roy. Meteor. Soc., 79, 317-341.

Martner, B. E., 1995: Doppler radar observations of mammatus. Mon. Wea. Rev., 123, 3115-3121.

_ 1996: An intimate look at clouds. Weatherwise, 49 (3), 20-23.

Ooyama, K. V., 2001: A dynamic and thermodynamic foundation for modeling the moist atmosphere with parameterized microphysics. J. Atmos. Sci., 58, 2073-2102.

Osthoff, H., 1906: Der Mammato-Cumulus (The mammatocumulus). Meteor. Z., 23, 401-408.

Pandya, R. E., and D. R. Durran, 1996: The influence of convectively generated thermal forcing on the mesoscale circulation around squall lines. J. Atmos. Sci., 53, 2924-2951.

Pasquill, F., 1962: Atmospheric Diffusion: The Dispersion of Windborne Material from Industrial and Other Sources. Van Nostrand, 297 pp.

Petre, J. M., and J. Verlinde, 2004: Cloud radar observations of Kelvin-Helmholtz instability in a Florida anvil. Mon. Wea. Rev., 132, 2520-2523.

Plank, V. G., D. Atlas, and W. H. Paulsen, 1955: The nature and detectability of clouds and precipitation as determined by 1.25-centimeter radar. J. Meteor., 12, 358-378.

Platt, C. M. R., R. T. Austin, S. A. Young, and A. J. Heymsfield, 2002: LIRAD observations of tropical cirrus clouds in MCTEX. Part II: Optical properties and base cooling in dissipating storm anvil clouds. J. Atmos. Sci., 59, 3163-3177. 
Pruppacher, H. R., and J. D. Klett, 1997: Microphysics of Clouds and Precipitation. $2 \mathrm{~d}$ ed. Kluwer Academic, $348 \mathrm{pp}$.

Quante, M., G. Teschke, M. Zhariy, P. Maaß, and K. Sassen, 2002: Extraction and analysis of structural features in cloud radar and lidar data using wavelet based methods. Proc. European Radar Conf., Delft, Netherlands, Eur. Meteor. Soc., 95-103.

Randall, D. A., 1980: Conditional instability of the first kind upside-down. J. Atmos. Sci., 37, 125-130.

Rayleigh, L., 1883: Investigation of the character of the equilibrium of an incompressible heavy fluid of variable density. Proc. London Math. Soc., 14, 170-177.

Rogers, R. R., and M. K. Yau, 1989: A Short Course in Cloud Physics. 3d ed. Pergamon Press, 293 pp.

Rose, W. I., and Coauthors, 1995: Ice in the 1994 Rabaul eruption cloud: Implications for volcano hazard and atmospheric effects. Nature, 375, 477-479.

, G. J. S. Bluth, D. J. Schneider, G. G. J. Ernst, C. M. Riley, and R. G. McGimsey, 2001: Observations of 1992 Crater Peak/Spurr volcanic clouds in their first few days of atmospheric residence. J. Geol., 109, 677-694.

- , and Coauthors, 2003: The February-March 2000 eruption of Hekla, Iceland from a satellite perspective. Volcanism and the Earth's Atmosphere, Geophys. Monogr., No. 139, Amer. Geophys. Union, 107-132.

_ - G. J. S. Bluth, and I. M. Watson, 2004: Ice in volcanic clouds: When and where? Proc. Second Int. Conf. on Volcanic Ash and Aviation Safety, OFCM, Washington, DC, 27-33.

Rust, W. D., R. Davies-Jones, D. W. Burgess, R. A. Maddox, L. C. Showell, T. C. Marshall, and D. K. Lauritsen, 1990: Testing a mobile version of a cross-chain loran atmospheric sounding system (M-CLASS). Bull. Amer. Meteor. Soc., 71, $173-180$.

Sassen, K., 2002: Cirrus clouds: A modern perspective. Cirrus. D. K. Lynch et al., Eds., Oxford University Press, 11-40 (text), 458-468 (figures).

— virga: Comments on "Is virga rain that evaporates before reaching the ground?" Mon. Wea. Rev., 121, 2426-2428.

—_, and Coauthors, 1995: The 5-6 December 1991 FIRE IFO II jet stream cirrus case study: Possible influences of volcanic aerosols. J. Atmos. Sci., 52, 97-123.

—_ J. M. Comstock, Z. Wang, and G. G. Mace, 2001: Cloud and aerosol research capabilities at FARS: The Facility for Atmospheric Remote Sensing. Bull. Amer. Meteor. Soc., 82, 1119-1138.

Schaefer, V. J., and J. A. Day, 1981: A Field Guide to the Atmosphere. Houghton Mifflin Co., 359 pp.

Schlatter, T., 1985: Mammatus clouds, sheltered thermometers. Weatherwise, 38, 216-217.

Schmauss, A., 1913: Der Mammatocumulus-Ein Beleuchtungseffekt? (The mammatocumulus-An illumination effect?) Meteor. Z., 30, 188-189.

Schneider, D. J., W. I. Rose, L. R. Coke, G. J. S. Bluth, I. E. Sprod, and A. J. Krueger, 1999: Early evolution of a stratospheric volcanic eruption cloud as observed with TOMS and AVHRR. J. Geophys. Res., 104, 4037-4050.

Schneider, K., 1920: Die Inversion an der Basis von Stratus Mammatus (The inversion at the base of stratus mammatus). Meteor. Z., 37, 137-139.

Schröder, F., and Coauthors, 2000: On the transition of contrails into cirrus clouds. J. Atmos. Sci., 57, 464-480.
Schultz, D. M., and R. J. Trapp, 2003: Nonclassical cold-frontal structure caused by dry subcloud air in northern Utah during the Intermountain Precipitation Experiment (IPEX). Mon. Wea. Rev., 131, 2222-2246.

and Coauthors, 2002: Understanding Utah winter storms: The Intermountain Precipitation Experiment. Bull. Amer. Meteor. Soc., 83, 189-210.

Scorer, R. S., 1958: The dynamics of mamma. Sci. Prog., 46, 75-82. - 1972: Clouds of the World. Stackpole Books, 176 pp.

Sharp, D. H., 1984: An overview of Rayleigh-Taylor instability. Physica D, 12, 3-18.

Slonaker, R. L., B. E. Schwartz, and W. J. Emery, 1996: Occurrence of nonsurface superadiabatic lapse rates within RAOB data. Wea. Forecasting, 11, 350-359.

Stewart, R. E., 1984: Deep $0^{\circ} \mathrm{C}$ isothermal layers within precipitation bands over southern Ontario. J. Geophys. Res., 89, 2567-2572.

Stith, J. L., 1995: In situ measurements and observations of cumulonimbus mamma. Mon. Wea. Rev., 123, 907-914.

Straka, J. M., D. S. Zrnić, and A. V. Ryzhkov, 2000: Bulk hydrometeor classification and quantification using polarimetric radar data: Synthesis of relations. J. Appl. Meteor., 39, 13411372 .

Taylor, G., 1950: The instability of liquid surfaces when accelerated in a direction perpendicular to their planes. Proc. Roy. Soc. London, A201, 192-196.

Troeger, H., 1921: Sonnenring und Stratus Mammatus (Sun ring and stratus mammatus). Das Wetter, 38, 190.

_ - 1922: Die Häufigkeit der Mammatus-Formen (The frequency of the mammatus). Meteor. Z., 39, 122-123.

Wagner, F., 1948: Mammatusform als Anzeichen für Absinkbewegung in Wolkenluft (The shape of mammatus as an indicator for subsidence in cloudy air). Ann. Meteor., 1, 336-340.

Wang, L., and K. Sassen, 2006: Cirrus mammatus properties derived from an extended remote sensing dataset. J. Atmos. Sci., 63, 712-725.

Warner, C., 1973: Measurements of mamma. Weather, 28, 394 397.

Wegener, A., 1909: Zur Entstehung des Cumulus Mammatus (About the formation of cumulus mammatus). Meteor. Z., 26, 473-474.

Winstead, N. S., J. Verlinde, S. T. Arthur, F. Jaskiewicz, M. Jensen, N. Miles, and D. Nicosia, 2001: High-resolution airborne radar observations of mammatus. Mon. Wea. Rev., 129, $159-166$.

Wurman, J., J. Straka, E. Rasmussen, M. Randall, and A. Zahrai, 1997: Design and deployment of a portable, pencil-beam, pulsed, 3-cm Doppler radar. J. Atmos. Oceanic Technol., 14, 1502-1512.

Yang, M.-J., and R. A. Houze Jr., 1995: Multicell squall-line structure as a manifestation of vertically trapped gravity waves. Mon. Wea. Rev., 123, 641-661.

Zahrai, A., and D. S. Zrnić, 1993: The 10-cm-wavelength polarimetric weather radar at NOAA's National Severe Storms Laboratory. J. Atmos. Oceanic Technol., 10, 649-662.

Zrnić, D. S., N. Balakrishnan, C. L. Ziegler, V. N. Bringi, K. Aydin, and T. Matejka, 1993: Polarimetric signatures in the stratiform region of a mesoscale convective system. J. Appl. Meteor., 32, 678-693. 